\title{
Defective Interfering RNA Viruses and the Host-Cell Response
}

\author{
John J. Holland, S. Ian T. Kennedy, Bert L. Semler, \\ Charlotte L. Jones, Laurent Roux, and Elizabeth A. \\ Grabau \\ Department of Biology \\ University of California, San Diego \\ La Jolla, California 92093
}

\section{INTRODUCTION}

This chapter will emphasize recently derived knowledge concerning the nature of defective interfering (DI) particles of RNA animal viruses, their biological origins and functions, and their involvement in long-term persistent infections. We will not attempt to review all of the DI literature, and we will confine ourselves to DI particles of RNA viruses. The previous review by Huang and Baltimore (1977) amply documents the occurrence and behavior of DI particles in a wide variety of DNA and RNA viruses and discusses their biological effects, and a very thorough recent review of rhabdovirus DI particles by Reichmann and Schnitzlein (1978) provides excellent in-depth coverage of many areas not covered by the present chapter as well as some alternate viewpoints of areas which are considered here. We will omit DNA virus DI particles from extensive consideration because of space limitations and because they are generally less well characterized at present. 
However, at the end of the chapter we will briefly cite recent studies implicating DI particles in some persistent infections by DNA viruses.

DI particles were first recognized in preparations of influenza virus propagated in vivo. The first clear definition of DI particles was that of von Magnus (1954) who showed that homologous interference exerted by the yields from serial undiluted passages of influenza virus in eggs was due to replication of "incomplete particles" which showed hemagglutinating and interfering ability but not infectivity. In fact, Henle and Henle (1943) first reported a "paradoxical behavior" in which lateharvest virus from eggs showed lower infectivity in mice when undiluted than when diluted one thousandfold. Because of the resistance of the interfering agent to UV light and heat, they concluded that interference was due to "inactivated" infectious virus, but their results were almost certainly due to the presence of DI particles. Cooper and Bellett (1959) and Bellett and Cooper (1959) showed that a similar phenomenon occurred with vesicular stomatitis virus (VSV) on undiluted passage in cell culture. They demonstrated that the interfering component was transmissible and that it sedimented more slowly than infectious virus. However, they were unable to rule out interferon and for some reason were unable to neutralize these DI particles with immune serum. Hackett (1964) demonstrated by electron microscopy that VSV DI particles were shorter than standard infectious virus, and several years later it was shown that discrete VSV DI particles could be separated from standard virus on sucrose gradients (Huang et al., 1966; Crick et al., 1966; Hackett et al., 1967). This allowed purification and study of the effects of DI particles (Huang and Wagner, 1966a). It is even possible to achieve greater than a billionfold purification of VSV DI particles by repeated cycles of velocity sedimentation in sucrose gradients and to obtain milligram quantities of DI particles totally freed of infectious virus for biological studies (Doyle and Holland, 1973). The converse, however, is not true-it is not possible to remove all DI particles from standard virus by velocity sedimentation because a percentage of the smaller DI particles will always aggregate and cosediment along with standard virus. However, VSV DI particles can be biologically eliminated or reduced in number by serial cloning (Stampfer et al., 1971). Small amounts of infectious virus picked directly from a plaque may be and usually are free of DI particles, but high-titer pools prepared directly from a plaque isolate are always contaminated by DI particles (Holland et al., 1976a). Since VSV generates DI particles at a rate of $10^{-7}-10^{-8}$ for each infectious standard virus particle replicated (Holland et al., 1976b), these DI particles are present in such low 
amounts that they cannot be visualized directly. They can be observed only after several further serial undiluted passages during which they undergo $10^{4}$-fold amplification during each passage (Holland et al., $1976 a, b)$ with support of the helper standard virus. Thus the need for serial undiluted passages in the "von Magnus phenomenon" is probably a requirement for amplification of DI particles and not for their generation. Removal of DI particles from standard virus is a particular problem for the paramyxoviruses since cloning alone does not work (Rima et al., 1977). To overcome this difficulty these authors suggest "an intermediate dilution of $1: 1000$ be used so that the virus growth period is relatively short."

Huang and Baltimore (1970) were the first to call attention to the widespread occurrence of DI particles among nearly all groups of animal viruses, and they proposed the name DI for virus particles which (1) lack a portion of the genome; (2) contain normal virus structural proteins; (3) can replicate only with the aid of helper standard infectious virus; and (4) interfere specifically with replication of homologous standard helper virus. Another important characteristic of DI particles is the fact that their generation and their interfering capacity may show enormous variability in different cell types (Choppin, 1969; Huang and Baltimore, 1970; Perrault and Holland, 1972a; Holland et al., 1976a). In the case of the positive-strand viruses, even the final size and structure of the DI genome is strictly controlled by the cell type which generates the DI particles (Stark and Kennedy, 1978). This is discussed in detail below.

Members of each group of the negative-strand viruses have been found to produce DI particles or DI-like particles. These include the orthomyxoviruses (e.g., influenza A), paramyxoviruses (e.g., Sendai, measles viruses), rhabdoviruses (e.g., VSV, rabies virus), arenaviruses (e.g., LCM and parana viruses), and probably bunyaviruses (e.g., La Crosse and Uukuniemi) (references are given below). Among the positive-strand RNA viruses of class IV (Baltimore, 1971), DI particles have been identified in stocks of picornaviruses (Cole et al., 1971; McClure et al., 1980) and togaviruses (Schlesinger et al., 1972). As yet, there has been no report of DI particles of any member of the coronavirus group, but this probably reflects the present paucity of information regarding the properties of the coronaviruses. Among the double-stranded RNA viruses, reovirus has clearly been shown to generate DI particles (Nonoyama et al., 1970), and there is suggestive evidence for DI particles of infectious pancreatic necrosis virus of trout (Nicholson and Dunn, 1972). 
The history of picornavirus, reovirus, and togavirus DI particles dates back to the early years of this decade. In 1970 Nonoyama et al. reported the presence of DI particles in reovirus stocks. The elegant studies of Cole et al. (1971) established the existence of poliovirus DI particles, and the following year two groups independently reported the existence of DI particles of the togavirus, Sindbis virus (SV) (Inglot and Chudzio, 1972; Schlesinger et al., 1972). For poliovirus, 16-18 serial passages in HeLa cells were required before DI particles became detectable. Fewer passages-six to eight-were required for SV DI particles to become apparent in virus stocks propagated in either chicken or hamster cells. With the exception of some recent work on mengovirus DI particles (McClure et al., 1980), poliovirus remains the only picornavirus system for which DI particles have been formally identified. Reovirus DI particles (Nonoyama and Graham, 1970) were detected after seven high-multiplicity passages of several different clones of type 3 reovirus. Almost all work concerning DI particles of togaviruses has been done with either SV or Semliki Forest virus (SFV), both alphaviruses. Very little has been reported about DI particles of flaviviruses.

In summary, DI particles are deletion mutants (usually genome recombinants) which cannot replicate by themselves and which interfere specifically with replication of the homologous infectious helper virus that they require for their own generation and replication. Below, we review their structural, biological, and biochemical properties and the evidence for their role in persistence. Because of their rather significant distinguishing characteristics, we will deal with the DI particles of negative-strand viruses separately from those of the positive-strand viruses.

\section{STRUCTURE AND GENOME ARRANGEMENT OF DI PARTICLES}

\subsection{Particles of Negative-Strand Viruses}

The structure of VSV and its DI particles with respect to overall morphology and protein composition has been reviewed (Huang, 1973; Wagner, 1975; Huang and Baltimore, 1977) and will not be reiterated here. For most of the negative-strand RNA viruses, the DI particles appear to be identical to the standard virus in both their protein composition and overall morphological characteristics. In some cases DI are smaller in size, however. 
The genome RNA of DI particles from negative-strand viruses has been characterized in a number of different ways. However, since most of the data on DI RNA structure comes from studies on VSV and Sendai virus, this section will focus almost entirely on these two viruses. Using velocity sedimentation and hybridization, it was originally shown for VSV (Huang and Wagner, 1966b; Brown et al., 1967; Schaffer et al., 1968) and Sendai virus (Kingsbury et al., 1970) that DI RNA is a deleted form of the standard virus RNA. In addition, it was shown by RNA-RNA annealing that any given DI particle contains a specific portion of the standard virus genome and not random pieces encapsidated into mature DI particles (Schincariol and Howatson, 1972; Stamminger and Lazzarini, 1974).

Identification of those virion genes represented within various VSV DI-particle isolates has been achieved by hybridization of purified DI RNAs to the purified mRNA fractions obtained from VSV-infected cell extracts (Leamnson and Reichmann, 1974; Stamminger and Lazzarini, 1974; Schnitzlein and Reichmann, 1976; Adler and Banerjee, 1976) and to the total mRNA synthesized in vitro by purified virions treated with detergent (Roy and Bishop, 1972). It was found that most of the DI RNAs originated from the $5^{\prime}$ end of the standard virus genome and that these DI particles exhibited homotypic interference. However, a single DI-particle isolate (HR DI) was unique in that it arose from the $3^{\prime}$ end of the standard virus RNA (Leamnson and Reichmann, 1974; Stamminger and Lazzarini, 1974; Schnitzlein and Reichmann, 1976). This isolate of Indiana DI particles was also unique in that it exhibited heterotypic interference with New Jersey VSV (Prevec and Kang, 1970; Schnitzlein and Reichmann, 1976). Its difference from nearly all other DI particles was further demonstrated when it was shown to be the only known DI particle to transcribe some functional mRNA both in vivo (Chow et al., 1977; Johnson and Lazzarini, 1977) and in vitro (Colonno et al., 1977), presumably because it has the transcriptional initiation site contained at the $3^{\prime}$ terminus of standard virus RNA. In addition, recent evidence has shown that the HR DI particle isolate contains RNAs with internal genome deletions that retain the standard VSV $3^{\prime}$ and 5' terminus (Perrault and Semler, 1979; Lazzarini, personal communication).

DI particles from VSV may contain minus strands (Roy and Bishop, 1972; Stamminger and Lazzarini, 1974) or unlinked plus and minus strands of RNA (Roy et al., 1973; Leamnson and Reichmann, 1974; Reichmann et al., 1974; Schnitzlein and Reichmann, 1976; Perrault and Leavitt, 1977a). Sendai RNA isolated from DI nucleocapsids 
obtained from the infected cell also appears to have considerable plus and minus strand polarity (Kolakofsky, 1976). In addition, a rather unique structural feature of the RNA of some isolates of VSV DI particles results from packaging of covalently linked plus and minus strands. These are referred to as "snap-back" RNA (Lazzarini et al., 1975; Perrault, 1976; Perrault and Leavitt, 1977a). It was suggested that this RNAse-resistant, snap-back structure may be a modified version of a normal VSV RNA replicating intermediate which becomes packaged into some types of DI particle (Perrault, 1976). It may have biological significance, since it has been detected at varying levels in quite a few different DI particle isolates (Perrault and Leavitt, 1977a).

The RNA from influenza virus DI particles was first shown to differ from standard virus RNA in that it completely or partially lacked the largest segment of viral RNA (Duesberg, 1968; Choppin and Pons, 1970). Other data (Bean and Simpson, 1976; Nayak et al., 1978) indicate that influenza DI particles do not always selectively lose a particular RNA segment. Instead, there appears to be a relative reduction of one or more of the four largest viral RNA segments packaged by DI particles concomitant with packaging of subviral-size RNAs. This rather nonspecific loss of viral RNA segments has been suggested as the basis for the loss of infectivity in influenza DI particles (Nayak et al., 1978). The apparent discrepancies in DI genome composition may be explained by a rather considerable variability in the reduction of viral RNA segments in DI RNA preparations obtained from different clones of influenza virus (Janda et al., 1979).

In addition to cistron representation and RNA packaging, recent work suggests that the RNA termini of DI particles may be important in DI particle generation and interference. Inverted complementary sequences have been found in Sendai virus (Kolakofsky, 1976; Leppert et al., 1977) and VSV DI RNAs (Perrault and Leavitt, 1977b; Perrault et al., 1978). These terminal "stem" sequences of RNA in Sendai virus vary in length from 110 to 150 nucleotide pairs, depending on which DI particle isolate they are derived from (Leppert et al., 1977). In VSV DI RNAs the terminal complementary regions span approximately 60 nucleotide pairs in those DI particles so far analyzed (Perrault and Leavitt, 1977b; Perrault et al., 1978). Hybridization studies with the isolated DI stems and standard virus genome indicate that only the $5^{\prime}$ and not the $3^{\prime}$ terminus of the standard virus RNA is conserved in the DI RNAs. This is true for both Sendai virus (Leppert et al., 1977; Kolakofsky et al., 1978) and VSV (Perrault and Leavitt, 1977b; Perrault et al., 1978). Additionally, the $3^{\prime}$ termini of most DI RNAs are 
complementary copies of the $5^{\prime}$ end of standard virus RNA. To date, the HR DI particle of VSV has the only DI RNA known to contain both the $3^{\prime}$ and $5^{\prime}$ termini of the standard virus and hence cannot form the terminally base-paired stems found in other DI RNAs (Perrault $e t$ al., 1978; Perrault and Semler, 1979). On the basis of these and other data, two similar models for DI particle generation employing a replicase-switching and copy-back mechanism have been proposed (Leppert et al., 1977; Huang, 1977). A possible role in DI-particle autointerference has been suggested for the inverted complementary terminal sequences (Perrault et al., 1978), as discussed below. Neither interference nor the proposed models for DI-particle generation can be based solely on RNA structure since other factors like protein type within the DI nucleocapsid also have an influence on the interference phenomenon (Schnitzlein and Reichmann, 1977). It is also likely that the generation of the HR DI particle and its interference with standard VSV occur by different mechanisms than the ones proposed since the structure of its RNA termini is different from that of other DI particles (Perrault and Semler, 1979).

Although most of the data concerning the $3^{\prime}$ and $5^{\prime}$ termini of standard and DI RNAs were obtained from electron microscopy and hybridization studies, the following studies employing nucleotide sequencing of VSV (Indiana serotype) RNAs have lent further support to the polarity assignments given to the various RNA termini:

1. The first 17 nucleotides at the $3^{\prime}$ end of the DI RNA are similar (but not identical) to those at the $3^{\prime}$ end of the standard virus RNA, and this similarity then diverges to a complete lack of homology for the next 50 or so nucleotides past the first 17 (Keene et al., 1978).

2. The sequence of the 46 nucleotide in vitro RNA transcript templated by the $3^{\prime}$ end of the DI RNA (Semler et al., 1978; Holland et al., 1978; Schubert et al., 1978) is significantly different from the sequence of the leader RNA (Colonno and Banerjee, 1978), which is known to be synthesized directly from the $3^{\prime}$ end of standard virus RNA (Colonno and Banerjee, 1976).

3. The sequence of the $5^{\prime}$ end of standard virus RNA is identical to the $5^{\prime}$ end of DI particle RNAs for at least 46 nucleotides in from the terminus (Perrault et al., 1978; Semler et al., 1979).

Our knowledge to date of the sequences at the $5^{\prime}$ and $3^{\prime}$ ends of VSV (Indiana serotype) and DI RNAs is presented in Fig. 1A and 


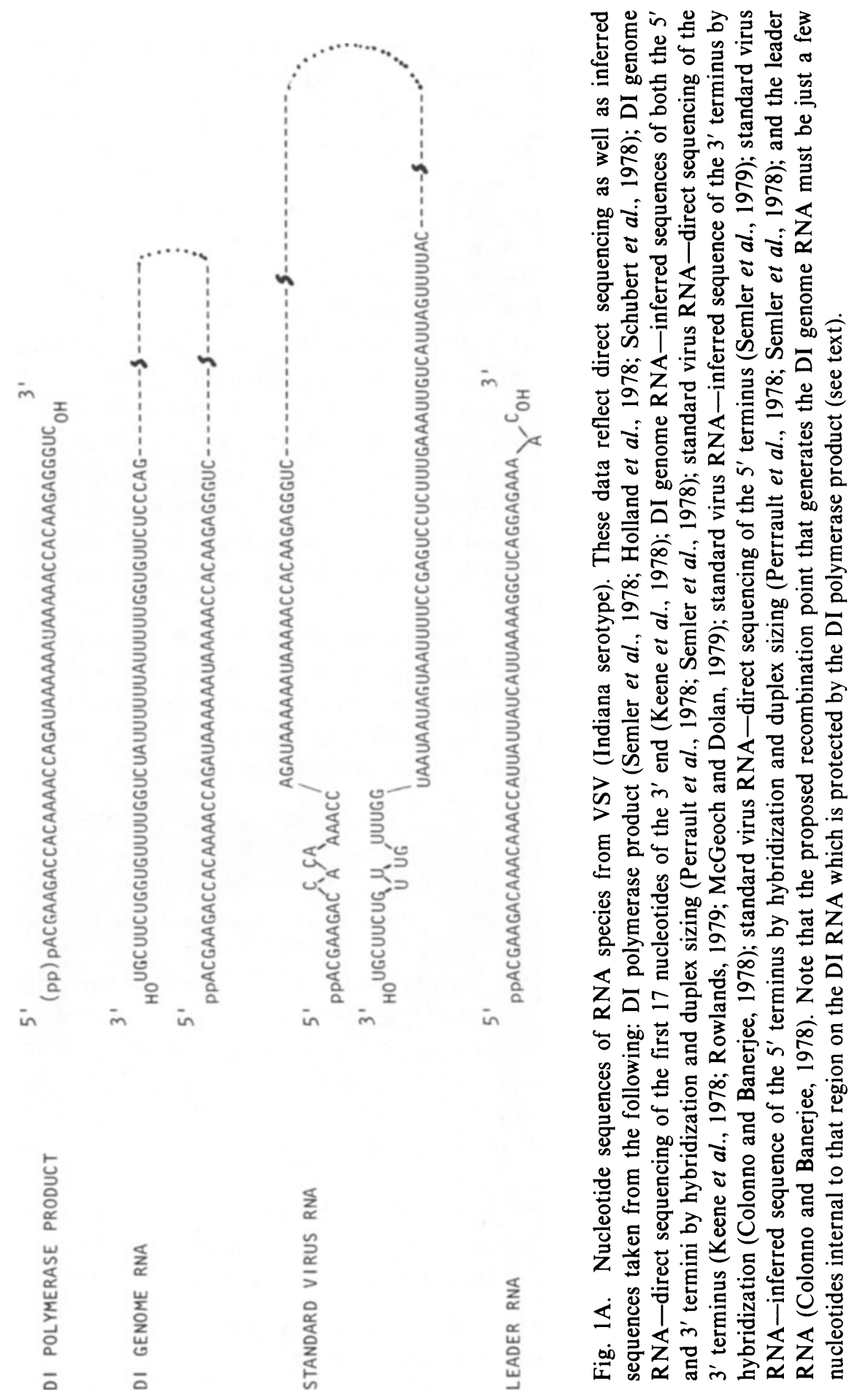




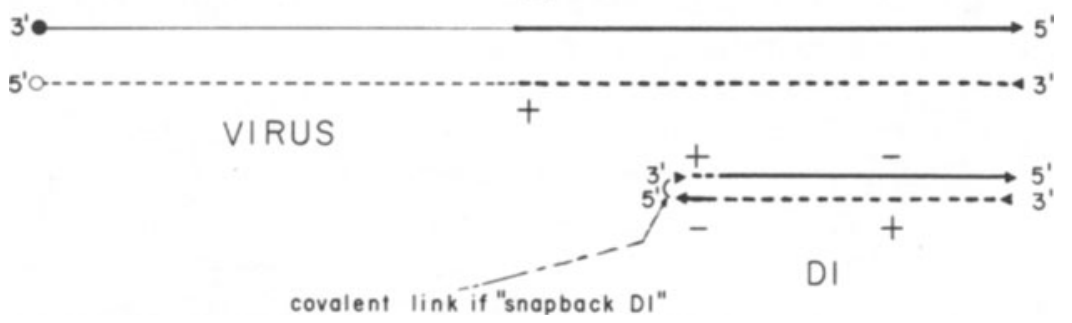

Fig. 1B. Schematic representation of VSV standard virus RNA and the DI RNA which is derived from it. The DI RNA has the same nucleotide sequence at the $3^{\prime}$ end (and the $5^{\prime}$ end) of both the plus and the minus strands, but the standard virus RNA has a different sequence at the $3^{\prime}$ end of its plus and minus strands despite some partial identity. Note that the $5^{\prime}$ terminus of the minus strand's virion RNA is conserved in the DI RNA, while the $3^{\prime}$ end is not. "Snap-back RNA" DI particles are a special type containing covalently linked plus- and minus-strand RNA. Thick lines indicate the $5^{\prime}$ half of the genome (encoding the L protein).

schematized in Fig. 1B. Since the stem structures are only slightly longer than the region coding for the DI polymerase product RNA, it is clear that the recombination point which generates most VSV DI particles is at the internal end of the stem sequence, and this is only slightly beyond (internal to) the end of the 46-nucleotide region coding for DI product RNA. Intriguingly, RNA sequence analysis has revealed a common hexamer oligonucleotide found in just this region for four different VSV DI-particle RNAs (Schubert et al., 1979), and it was proposed that this hexamer may represent a specific internal replicase recognition site that is a necessary aspect of the strand-switching and copy-back models for DI-particle generation. Further sequencing of other DI-particle RNAs and replicase binding experiments will determine the importance of such sequences in DI-particle generation.

Whether these structures are a general feature in other negativestrand DI particles must await further investigation. Evidence from electron microscopy of other negative-strand virus groups has shown circular nucleocapsid structures as well as linear molecules of greater than normal length. These have been reported for measles-infected cells (Thorne and Dermott, 1976), and from virions of LaCrosse virus (Obijeski et al., 1976) and Lumbo virus (Samso et al., 1975) (two serologically related bunyaviruses). Circular nucleocapsids as well as circular RNAs have been observed in Uukuniemi virus which is an unrelated bunyavirus (Petterson and von Bonsdorff 1975; Petterson and Hewlett, 1976; Hewlett et al., 1977). The status of any of these structures as DI-particle components is unclear. All of these could be indicative of inverted complementary terminal sequences, but proof awaits 
further biochemical and nucleotide sequence analysis of RNAs from these and other negative-strand virus groups.

\subsection{Particles of Positive-Strand Viruses}

Because the genome of DI particles is a truncated form of the standard virus genome, the size of DI particles is often smaller than that of the standard virus (e.g., VSV, see above). This difference is commonly employed as an experimental basis for the physical separation of DI particles from their standard virus. The physical difference, in turn, facilitates the characterization of the DI-particle genome. For the positive-strand RNA viruses this difference, although greater for the picornaviruses than for the alphaviruses, is considerably less than for rhabdoviruses. Thus for poliovirus several cycles of density-gradient centrifugation are required to effect essentially complete purification of its DI particles. The modest difference between the buoyant density of poliovirus and its DI particles is reflected in the relatively small difference between the size of the DI genome and that of the standard virion. Figure 2 shows an RNA-RNA duplex between poliovirus DI RNA and negative-strand RNA from replicative form (Nomoto et al., 1978). This technique, together with other techniques which probe the sequence relationship between standard and DI poliovirus RNA, clearly established that about $13-16 \%$ of the nucleotide sequence of standard virus RNA is deleted in the DI RNA and that this deletion is located about $20 \%$ inward from the $5^{\prime}$ end of the standard virus genome. This latter observation is in agreement with the earlier finding that the deletion in poliovirus DI RNA maps in the N1 region which from biochemical and genetic analysis was shown to be in the $5^{\prime}$ terminal half of the genome (Cole and Baltimore, 1973a). In a recent study Lunquist et al. (1979) showed that at least five distinct types of polio DI particles can be generated and that single, double, and possibly triple deletions can occur in the viral genome. All of these mutations occur in the capsid gene region. In addition, despite their heterogeneity, the DI genomes are quite similar in physical size.

For SV and SFV there is even less difference between the buoyant density of the standard virion and its DI particles than for the poliovirus counterparts. Two reports (Shenk and Stollar, 1973; Bruton and Kennedy, 1976) suggested that alphavirus DI particles can be slightly more dense than the standard virus. Other workers (Weiss and Schlesinger, 1973) failed to resolve standard and DI SV particles on 


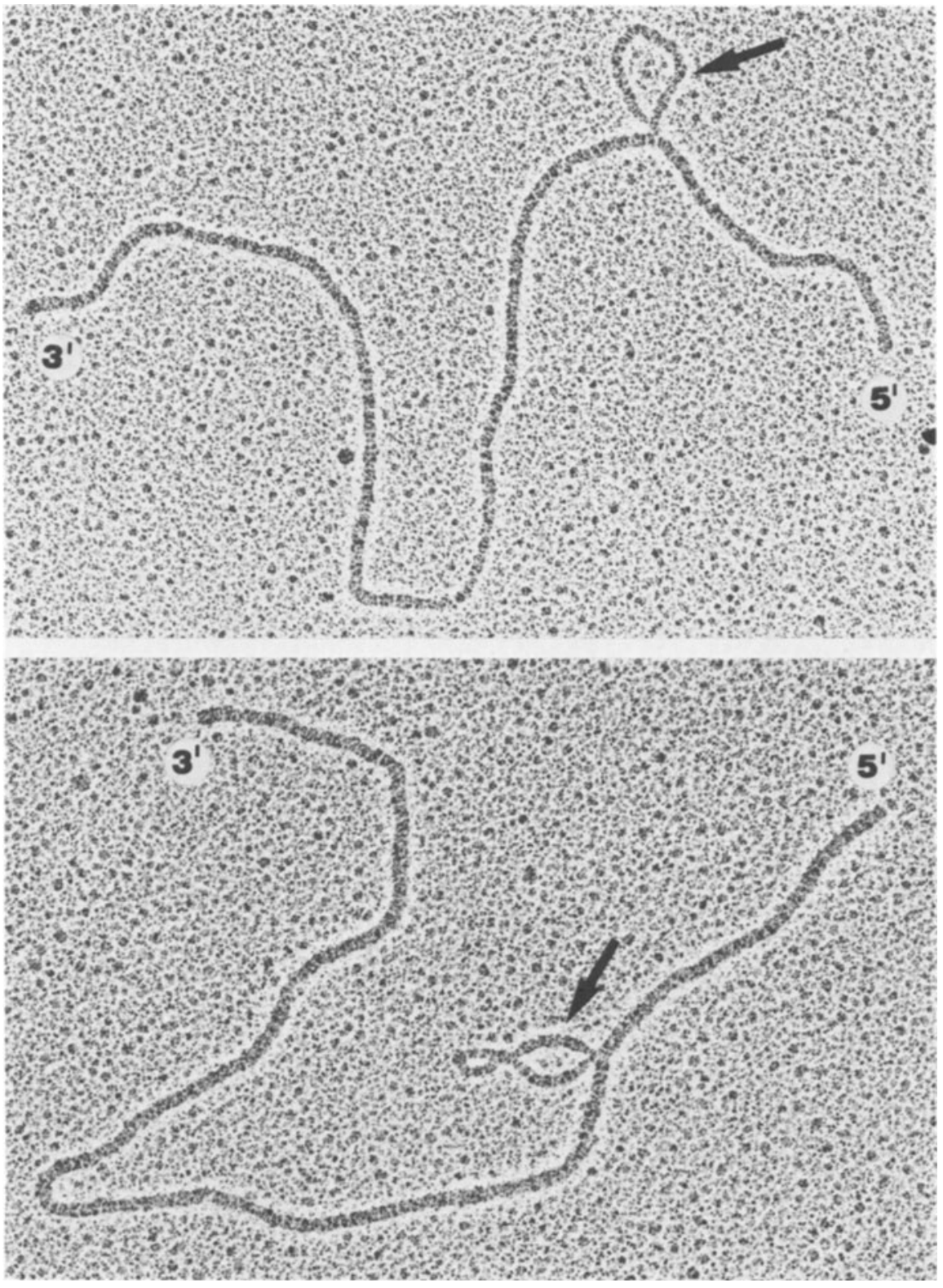

Fig. 2. Electron micrograph of an RNA-RNA duplex formed between poliovirus DI RNA and negative strand from RF isolated from cells infected with standard virus. From Nomoto et al. (1978) with permission. 
density gradients. The reason for the similarity in the density of standard and DI alphaviruses is, however, unrelated to that of the poliovirus system. From ribonuclease $T_{1}$ oligonucleotide fingerprinting (Kennedy, 1976; Kennedy et al., 1976) it was clearly established that the nucleotide sequence of alphavirus DI RNA is only a very small fraction of that of the standard virus genome. Therefore, in order to reconcile this marked sequence difference between standard and DI particle RNA with the close similarity between the buoyant density of standard and DI particles, it was suggested that each alphavirus DI particle contains several copies of DI RNA (Kennedy et al., 1976). Indeed, there may be intracellular packaging "rules" which put into each nucleocapsid one standard virus RNA (molecular weight $4.4 \times 10^{6}$ ) or the almost exact mass equivalent of DI RNA. This mass equivalent may be two molecules of half-length DI RNA, three molecules of about one-thirdlength RNA, and so on up to six molecules of about one-sixth-length RNA. (We shall consider this point again later.) How these several copies of DI RNA are arranged in the DI particle is not known, but the observation that they can exist as circles with short panhandle tails (Fig. 3a) suggests that they may form concatameric structures of the type shown in Fig. 3b. These structures would be formed by hydrogen bonding between a short nucleotide sequence at the $5^{\prime}$ end of the DI RNA and its inverted complement at the $3^{\prime}$ end either within the same strand (to form a circle) or between strands (to form a concatamer). Inverted complementary nucleotide sequences have been shown to exist

a

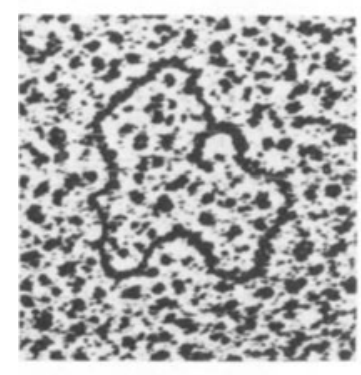

b

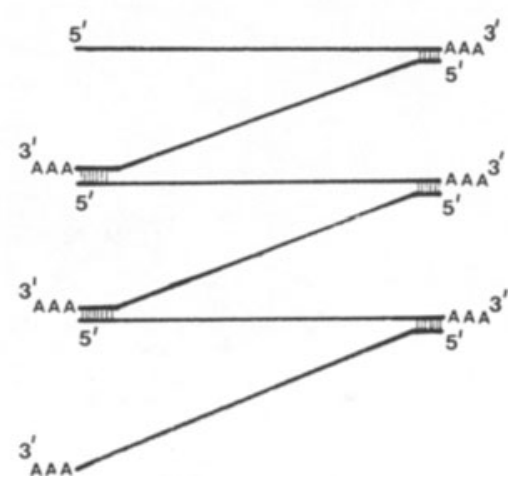

Fig. 3. Conformation of SFV DI RNA. (a) Electron micrograph of DIssD RNA (see Fig. 4) from purified DI particles of SFV. The RNA was spread under partially denaturing conditions (Simons and Kennedy, unpublished). (b) Schematic representation of six molecules of alphavirus DI RNA arranged in a concatamer. 

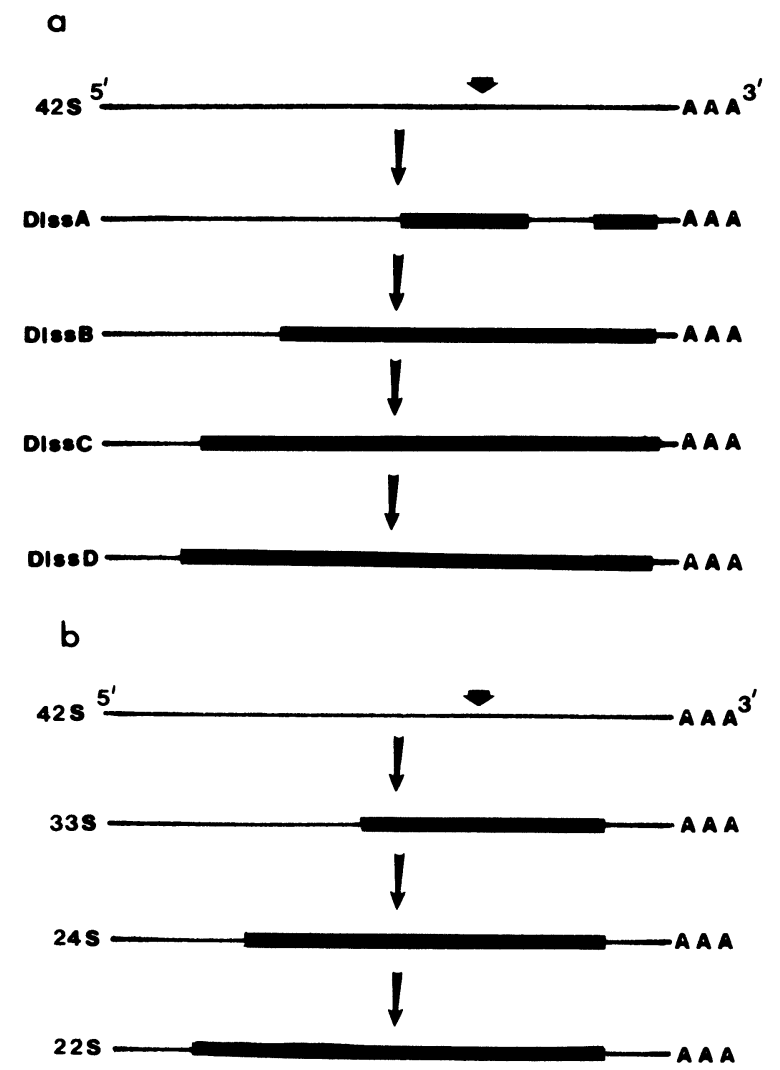

Fig. 4. Sequence organization of alphavirus DI RNAs. For SFV (a) the DI RNAs are denoted DIssA, DIssB, DIssC, and DIssD (Stark and Kennedy, 1978); for SV (B) the DI RNAs are denoted $33 \mathrm{~S}, 24 \mathrm{~S}$ and $22 \mathrm{~S}$ according to their sedimentation coefficient (Guild and Stollar, 1977). The denotes deleted sequences which are approximately to scale. The heavy arrows indicate the junction between the nonstructural (polymerase) genes (to the left) and the structural genes in standard virus 42 S RNA.

at the ends of both standard and DI SFV RNA (Kennedy, unpublished observations).

Using oligonucleotide fingerprinting (Kennedy, 1976; Stark and Kennedy, 1978) and RNA-RNA hybridization (Guild and Stollar, 1977), the sequence arrangements shown in Fig. 4 have been established for standard RNA and the RNA of several DI particles generated during the course of high-multiplicity serial passaging of SV and SFV. Several points emerge from these studies. First, during the serial passaging, several species of DI RNA appear. Second, in all cases the $5^{\prime}$ and $3^{\prime}$ extremities of standard virus RNA are retained in DI RNA. 
Thus all species of alphavirus RNA are internally deleted forms of the standard genome. Third, with the exception of minor deletion differences, the deletions which generate SFV DI RNA (Fig. 4a) are very similar to those generating SV DI RNA (Fig. 4b). In addition to these sequence relationship findings several groups have observed that during the course of serial passaging the size of alphavirus DI RNA progressively decreases (Johnston et al., 1975; Guild et al., 1977; Stark and Kennedy, 1978). These two sets of observations strongly suggest that during serial passaging a series of sequential internal deletions occurs whereby each DI RNA acts as progenitor for the next smallest in the series until the smallest DI RNA of all (e.g., DIssD for SFV) is generated. For both SV and SFV this is an RNA with a molecular weight one-sixth that of the genome.

Reovirus DI particles have essentially the same buoyant density as standard virus. However, DI-particle cores can be resolved from those of standard virus. The density difference is consistent with the observation that the largest $\left(L_{1}\right)$ segment of the ten-segment double-stranded RNA genome is missing in DI particles (Nonoyama and Graham, 1970). Interestingly, however, no smaller, deleted version of the $L_{1}$ segment is apparent, which by analogy with DI particles of influenza virus might have been expected (see above). A second study of reovirus DI particles has shown that temperature-sensitive mutants of groups $\mathrm{C}$ and $\mathrm{F}$ more rapidly generate DI particles than wild-type virus. In this case the $\mathrm{L}_{1}$ segment is missing but on further passage another segment is deleted (Schuerch et al., 1974).

\section{MECHANISMS OF DI-PARTICLE GENERATION, REPLICATION, AND INTERFERENCE}

\subsection{Particles of Negative-Strand Viruses}

This section must involve some speculation on the biochemical mechanisms of DI-particle generation, replication, and interference. These can only be inferred but cannot be proved from data presently available.

\subsubsection{DI-Particle Generation}

Mechanisms of DI-particle generation remain undefined since some complex recombination mechanism must occur to shorten the 
virus genome internally and to add a new $3^{\prime}$ terminus which is a copy of the standard virus 5' terminus (see above). The "strand-switching, copyback" model proposed by Leppert et al. (1977) and Huang (1977) (in which the viral replicase falls off its template RNA, reattaches to the nascent RNA, and "reads back" on the nascent RNA) is a very plausible one, but experimental support is lacking since DI-particle generation takes place within the confines of an infected cell. Obviously, any inter- or intramolecular recombination event, whether legitimate (involving regions of sequence homology) or illegitimate, would be compatible with the data presently available. Indeed, it is not clear whether the recombination event occurs during replication at the positive- or negative-strand level or, alternatively, whether a splicing event occurs. Simple-minded in vitro attempts to generate DI particles or modify their size (by mutagenesis or by shear breakage of standard virus or DI nucleocapsid) do not succeed (Holland et al., 1976a). Furthermore, future attempts to achieve DI-particle generation in vitro by enzymatic or other means of RNA genome rearrangement will be hampered by the fact that naked virion RNA from negative-strand DI particles is biologically inactive (Holland et al., 1976a). The minimal infectious structure is the membrane-free nucleocapsid (Brown et al., 1967; Holland et al., 1976a), and in vitro reassembly has yet to be achieved with any negative-strand virus or DI nucleocapsid.

It can be demonstrated using low-titer clonal isolates that VSV DI-particle generation is a rather random event, and any DI-particlefree clone can generate a wide array of different-size DI particles in different passage series from the clone (Holland et al., 1976a). Others have reported that single clones seem to have a genetic capacity to regularly generate the same DI particles in a given cell type (Reichmann et al., 1971; Kang et al., 1978). However, this result is inevitable whenever the starting clone of virus is contaminated with DI particles which amplify during subsequent passage series, and both of these investigations started with high-titer virus pools prepared from clonal isolates. Since the rate of DI particle generation is about $10^{-7}-10^{-8}$ per infectious particle replication (Holland et al., 1976b), any VSV pool containing more than about $10^{7}-10^{8}$ pfu must be suspect with regard to the possibility that DI particles are already present. Ideally, a very early small plaque should be picked and used for such studies if the isolate contains $10^{6}$ or less total infectious virus pfu. The multipleplaque harvest technique of Stampfer et al. (1971) is a good method to obtain low-titer virus pools free or nearly free of DI (Holland et al., $1976 b$ ). Kolakofsky (1979) has also found random generation of dif- 
ferent DI particles of Sendai virus on independent serial passages of a multiply cloned plaque isolate, and Janda et al. (1979) have obtained similar results with some clones of influenza virus. Recently, a major technical advance for the preparation of VSV pools free of DI particles has been reported (Kang and Allen, 1978). Pretreatment of host cells with actinomycin D before virus growth was reported to deplete a hostcell factor required for DI particle generation. This technique has not been repeated by others, so its general applicability is not yet known.

\subsubsection{DI-Particle Replication and Interference}

The most notable fact regarding negative-strand virus DI-particle replication is their complete inability to replicate RNA without helper infectious virus. This is in contrast to DI particles from some positivestrand viruses such as poliovirus, which can carry out viral RNA synthesis but lack genetic information encoding capsid proteins (see below). The vast majority of VSV DI particles are nontranscribing and therefore genetically inert (Huang and Manders, 1972; Perrault and Holland, 1972b). The one known transcribing VSV DI particle (HR DI) does not code for the $\mathrm{L}$ protein, a major transcriptase and replicase polypeptide (Colonno et al., 1977), but it has been reported to be capable of killing cells (Marcus et al., 1977).

DI-particle interference was suggested independently by Huang and Manders (1972) and by Perrault and Holland (1972b) to be due to competition between DI particles and infectious virus RNA templates for viral replicase molecules. This replicative competition model was based on the following observations: (1) DI particles are genetically inert but replicate well in the presence of helper virus; (2) DI particles contain all the proteins of the helper virus; (3) DI particles do not inhibit primary transcription of standard virus added to cells in large amounts in the presence of cycloheximide; (4) DI particles strongly inhibit the replication of full-size viral genome RNA following primary transcription in the absence of cycloheximide, and there is a parallel inhibition of synthesis of the large amounts of viral messenger RNA normally transcribed from these secondary (newly replicated) viral RNA templates; (5) concomitant with this suppression of standard virus RNA replication and secondary messenger RNA transcription there is a striking synthesis of DI genome-size RNA (i.e., DI particle RNA replication). All these results strongly suggest but do not prove that DI particles compete at the replicative level. An even stronger 
indication for replicative interference is given by the fact that in pig kidney cells in which VSV DI particles do not interfere (Perrault and Holland, 1972a) there is no strong inhibition of viral RNA or viral messenger RNA synthesis despite high levels of replication of DI genome-size RNA in the same cells (Perrault and Holland, 1972b). Khan and Lazzarini (1977) have repeated and extended these replicative competition studies and conclude also that replicase competition could explain interference. However, it should be recognized that DI-particle interference could involve a number of mechanisms, including perhaps effects on viral protein synthesis or turnover rates. Rima and Martin (1979) report that measles virus DI particles cause a selective inhibition of synthesis of all other measles virus proteins except the $\mathrm{N}$ protein. However, Little and Huang (1977) found that DI interference caused no selective inhibition of synthesis of VSV proteins.

Khan and Lazzarini (1977) and Schnitzlein and Reichmann (1977) observed that there is much less interference by Indiana serotype DI particles when coinfecting cells with VSV New Jersey serotype helper virus even though the VSV Indiana DI particles replicate well with the heterotypic helper virus. Thus DI-particle replication can be dissociated from virus replication in heterotypic interference just as it can be from homologous interference in "low-interference" cell lines such as pig kidney cells (Perrault and Holland, 1972a). This ability to obtain DIparticle replication with little or no interference under certain conditions does not eliminate replicase competition as the site of interference (wherever interference does occur). In fact, Schnitzlein and Reichmann (1977) obtained strong heterotypic interference if the VSV Indiana DI genome RNA was encapsidated within VSV New Jersey proteins by one prior cycle of replication in the presence of VSV New Jersey helper virus. Clearly, the interaction of viral proteins with each other is important in determining the replicative and interfering efficiency of DI nucleocapsid templates. Furthermore, the reduced availability of viral proteins (resulting from reduced viral mRNA synthesis) may render replicative and interference phenomena more complex if limited availability of viral matrix and glycoprotein membrane proteins results in a buildup of DI and viral nucleocapsids within the cytoplasm. Also, the existence of low-interference cell lines (Choppin, 1969; Huang and Baltimore, 1970; Kingsbury and Portner, 1970; Perrault and Holland, 1972a; Holland et al., 1976a) suggests a major role of cellular factors in determining DI-particle interference. These factors may act as replicase components or in other ways. Obviously, interference mechanisms remain largely unexplored at the biochemical level, and definitive 
studies may require development of cell-free replication systems. Even if the replicase competition model proves to be substantially correct, quantitative regulatory aspects may prove to be more important than qualitative mechanisms. DI genome size could well be a factor in interference among the positive-strand RNA viruses (see below), but it appears to play little if any role in interference by negative-strand RNA viruses since large, medium, and small DI particles replicate and interfere with about equal efficiency. In growth competition experiments the smallest DI particles do not seem to replicate faster and hence outcompete larger DI particles; on the contrary, DI particles of various sizes outcompete other DI particles of various sizes in a random manner depending to a considerable extent on the cells in which they are replicating (Holland et al., 1976a).

Finally, it is clear that the structure of the DI RNA genome is important in interference since Prevec and Kang (1970) observed heterotypic interference with New Jersey serotype VSV by VSV DI particles of the HR (transcribing DI) class. Further sequencing and interference studies are needed to compare this unique class of DI particles to the major class of DI particles. This may be difficult at present because all stocks of HR DI which we have examined are contaminated with other DI particles of the nontranscribing class (Holland, unpublished), Adachi and Lazzarini (1978) and Reichmann and Schnitzlein (1978) have reported that their preparations of HR DI do interfere normally. The differences in the $3^{\prime}$ end sequences in this DI class as compared to the majority class predict that it should behave quite differently in interference (at least if the altered $3^{\prime}$ ends of the majority class of VSV DI particle are critical determinants of DI replicative and interfering ability as has been suggested (Perrault et al., 1978). Most VSV DI particles contain the same RNA sequence at the $3^{\prime}$ end of both their minus-strand and plus-strand RNA homologues (Perrault et al., 1978). Since this sequence is found only at the $3^{\prime}$ end of the plus (but not the minus) strand RNA of the standard infectious virus, any selective affinity for this sequence by the viral replicase should favor DI-particle replication over standard virus replication. This model would also predict that a completely pure preparation of the unique HR DI particle with RNA whose $3^{\prime}$ end is identical to that of standard virus RNA would not exhibit homologous interference as effectively as that of the major class of VSV DI particles. If the HR DI preparation of Reichmann and Schnitzlein (1978) and Adachi and Lazzarini (1978) (which exhibited strong interfering ability) was free of significant levels of the major class DI, then the new RNA $3^{\prime}$ end 
possessed by the major class DI must not be a critical requirement for interference. Another possible explanation for the replicative advantage and interfering ability of DI particles lies in the fact that the recombination point which generates the inverted "stems" is about 60 nucleotides or less from the 3' end of each DI RNA molecule (Perrault et al., 1978). This nearby recombination point might greatly alter the secondary and tertiary structure of DI RNA $3^{\prime}$ ends and greatly increase their affinity for replicase as compared to standard virus RNA $3^{\prime}$ ends. Since DI particles arise at a rather high frequency, only those $3^{\prime}$ end recombinants with a favorable replicase affinity would replicate preferentially and be selected. Clearly, our knowledge of the mechanisms of interference is still fragmentary.

\subsection{Particles of Positive-Strand Viruses}

\subsubsection{DI-Particle Replication and Interference}

Interference with standard virus multiplication by DI particles of poliovirus and alphaviruses occurs at the level of standard virus RNA synthesis and proviral assembly. For reovirus neither the mechanism of interference nor of enrichment is known. Two distinct functional classes of viral RNA are found in cells infected with either standard poliovirus or standard alphaviruses. These are single-stranded positive-polarity RNA and replicative intermediate (RI) RNA. For poliovirus a single size of positive-strand RNA (35 S) exists which acts as mRNA for both the viral structural proteins and polymerase polypeptides. In contrast, cells infected with standard alphaviruses contain two size classes of positive-strand RNA. The first of these (42 S RNA) is the viral genome and acts in the infected cell as mRNA for the polymerase polypeptides. The mRNA for the alphavirus structural proteins is a subgenomic fragment (26 S RNA) whose nucleotide sequence is the $3^{\prime}$ terminal onethird of $42 \mathrm{~S}$ RNA. For both poliovirus and the alphaviruses, RI RNA consists of genome-length template RNA to which is hydrogen bonded several nascent RNA strands. This class of RNA is probably derived from cytoplasmic replication complexes active in the synthesis of both positive- and negative-strand viral RNA.

Cells infected with alphavirus DI particles alone or with DI particle RNA do not synthesize any virus-specified components (Bruton et al., 1976). Thus alphavirus DI particles, although adsorbed, appear totally unable to initiate any virus-specific synthetic event. The reason 
for this inertness lies in the sequence relationship between standard virus RNA and DI RNA (see previous section). All alphavirus DI RNAs have a deletion across the junction region between the polymerase and structural protein genes in $42 \mathrm{~S}$ RNA. Since the polymerase genes are translated to form a polyprotein whose $C$-terminal coding region is absent in all the DI RNAs, these RNAs, even if potentially capable of translation (i.e., are capped, polyadenylated, and have a ribosome binding site; Kennedy, unpublished; Bruton et al., 1976; Clegg and Kennedy, unpublished), would seem a priori to be unable to direct the synthesis of functional polymerase and therefore unable to initiate the first step in multiplication. That this is a reasonable hypothesis to account for the metabolic inactivity of alphavirus DI particles is supported by the finding that neither SV DI RNA nor SFV DI RNA can serve as mRNA either in vitro or in vivo (Weiss et al., 1974; Bruton et al., 1976).

Cells coinfected with alphavirus stocks which contain DI particles synthesize several species of virus-specific RNA distinct from those which characterize multiplication of standard particles alone. These new species comprise not only single-stranded (ss) DI RNAs but also RI RNAs whose template strands are involved in replicating these ss DI RNAs (Weiss et al., 1974; Bruton et al., 1976; Kennedy et al., 1976; Guild et al., 1977). In addition, the total amount of viral RNA synthesis in cells coinfected with DI particles plus a given amount of standard virus is less than that in cells infected with the same amount of standard virus alone (Guild and Stollar, 1975). This reduction in total viral RNA synthesis depends on the ratio of DI particles to standard virus in the inoculum. The recognition of intracellular DI RI RNA, the lack of mRNA function of the ssDI RNA, and their sequence relationship to the standard genome, together with the dependence of total virus-specified RNA on the input ratio of DI particles to standard virus, all have led to the following model for alphavirus interference and selective propagation. Since all species of positive-strand DI RNA have the same $3^{\prime}$ nucleotide sequence as standard viral RNA, it seems likely that DI RNA and standard viral RNA can compete with one another for available viral polymerase. Since DI RNA is shorter than $42 \mathrm{~S}$ RNA, in a given period of time more DI negative-strand RNA than 42 S negative-strand RNA will be made. Since the DI and standard negative-strand RNAs also have common $3^{\prime}$ termini, competition for polymerase will again occur and, using the same length-difference argument, more DI positive-strand RNA than $42 \mathrm{~S}$ (or $26 \mathrm{~S}$ ) positive-strand RNA will be synthesized. These two "competition" 
processes, when operating sequentially, result not only in a marked reduction in the synthesis of all standard virus RNAs compared to their DI counterparts but also in a selective propagation of DI particles over standard virions. Although it may merely be the marked difference in length between DI and standard RNA which results in the synthesis of the former at the expense of the latter, other factors such as a greater affinity of DI RNA standard virus RNA for polymerase may also play a role. For example, the secondary and/or tertiary structure of the RNAs may determine their relative rates of replication at the intiation and/or elongation stage. In any event the model not only affords an explanation for interference by and selective propagation of alphavirus DI particles but also predicts that as soon as a short DI RNA is generated it will compete for polymerase not only with standard virus RNAs but also with any longer DI RNAs present in the same cell. This prediction has recently been confirmed for SV DI RNA (Guild et al., 1977) and SFV DI RNA (Stark and Kennedy, 1978). In addition, it now seems clear that foreshortening of alphavirus DI RNA occurs by a process of sequential internal deletions (see preceding sections). A second level at which interference may occur in the alphavirus system is in nucleocapsid assembly. Since the extent of structural protein synthesis is determined by the level of $26 \mathrm{~S}$ RNA, interference with the synthesis of this RNA by mechanisms discussed above will reduce synthesis of structural proteins. Consequently, newly synthesized genomic 42 S RNA and positive-strand DI RNA will compete for available structural proteins, specifically, available nucleocapsid protein. To what extent this level of competition plays a role in determining the overall decrease in standard virus multiplication is not known, but if it does play a role it is likely to be a minor one.

One notable feature of the alphavirus DI system is the marked effect exerted by the host cell on the generation and replication of DI particles. This effect was first recognized by Levin et al. (1973). In a more detailed study Stark and Kennedy (1978) showed that certain types of cell-for example, the mouse 3T3 cell and the rat NRK cell-generate and enrich SFV DI particles extremely rapidly such that within three or four passages the yield of standard virus has dropped by two to three orders of magnitude, and DI particles constitute over $95 \%$ of the final progeny. By contrast, 12 passages are required to generate detectable DI particles in pig PK 15 cells, and 20 passages are necessary in one line of HeLa cells. However, the deletion pathway of DI RNA is the same in all the cell types, and in almost every cell type the size and nucleotide sequence of the final DI RNA (DIssD; Fig. 4) which is 
generated are the same. Pig PK15 (Stark and Kennedy, 1978) cells are, however, an interesting and to date a unique exception in that they appear unable to support the final two deletion events, and the "terminal" DI particles contain DIssB (FIg. 4). The host cell, then, determines the timing of generation and even the kinetics of enrichment, i.e., the differential rate of multiplication of DI particles compared to standard virus and even the competitive ability of a larger DI RNA when a shorter one appears. However, it (the cell) plays little if any direct role in determining the primary nucleotide sequence of the DI RNAs, this property being the exclusive domain of the virus.

Alphavirus multiplication occurs not only in vertebrate but also in invertebrate cells (e.g., Stevens, 1970; Davey and Dalgarno, 1974). Early attempts to generate SV DI particles in invertebrate (mosquito) cells by high-multiplicity serial passaging failed (Igarashi and Stollar, 1976), as did attempts in those cells to replicate DI particles generated in a vertebrate cell system (Eaton, 1975; Igarashi and Stollar, 1976). Recently, we have been examining the generation of SFV DI particles in several clones derived from the original Aedes albopictus mosquito cell line of Singh (1967). In contrast to earlier findings both we and Logan (1979) have observed that several cell clones, all of which support the multiplication of standard SFV to levels greatly exceeding that obtained with uncloned cells, generate DI particles in the very first cycle of multiplication. furthermore, the DI RNA of these particles is indistinguishable by oligonucleotide mapping from that of particles generated in the vertebrate cells (Tooker and Kennedy, submitted). In addition, these several clones permit the multiplication of DI particles generated in vertebrate cells. Thus it now appears that at least a proportion of the cells in uncloned stocks of $A$ albopictus cells are indeed capable of generating and replicating SFV DI particles and that these particles are identical to those produced in the vertebrate cell. We shall return to the question of DI particles in invertebrate cells when we consider alphavirus persistence (see next section).

In marked contrast to alphavirus DI RNA, poliovirus DI RNA is capable of acting as mRNA (Cole and Baltimore, 1973a,b). However, although coding for polymerase, poliovirus DI RNA does not contain a functional set of capsid genes, and consequently no progeny particles are produced in cells infected with DI particles alone. In coinfected cells standard RNA and DI RNA appear to be replicated independently of one another, each with its own RI RNAs. Moreover, and again unlike the alphavirus system, the total level of viral RNA synthesis in cells coinfected with standard and DI poliovirus is essentially the same as in 
cells infected with standard virus alone. Since infected cells are limited to the extent of total viral RNA synthesis which they can support, the replication of standard virus RNA in coinfected cells in decreased by a percentage which is close to the percentage of DI particles in the inoculum. Synthesis of procapsid is reduced by a similar amount. Furthermore, DI and standard RNA compete for available procapsid in the assembly of progeny particles. These two levels of interference are independent of one another and multiply together so that the percentage of standard virus produced in co-infected cells is the square of the percentage of standard virus in the inoculum. The enrichment of poliovirus DI particles is about $6 \%$ per multiplication cycle (Cole and Baltimore, 1973c). This value is small compared to that of the alphaviruses, where, depending to an extent on the host cell, enrichment is between $20 \%$ and $80 \%$ per multiplication cycle. Presently, it is unclear at the molecular level how poliovirus DI enrichment occurs, but pulses of inhibition of protein synthesis during virus multiplication in coinfected cells have suggested that enrichment occurs early-perhaps during the first cycles of RNA synthesis (Baltimore et al., 1974).

\subsubsection{DI-Particle Generation}

The molecular mechanism of genesis of poliovirus and alphavirus DI particles, like that of all other DI systems, is obscure. One of the simplest hypotheses is that, having initiated RNA synthesis, the polymerase detaches from its template and rejoins it downstream near the $5^{\prime}$ end. Alternatively, if splicing occurs at either the nascent or posttranscriptive level, then a mistake in this process could generate a DI RNA. At this time, however, there is no evidence that splicing occurs in the normal fashioning of either picornavirus or alphavirus RNAs. It is also unclear whether deletion occurs during the synthesis of positivestrand RNA or negative-strand RNA. However, it is clear that the host cell can greatly influence the genesis of DI RNA. For example, in 3T3 cells, SFV particles are generated within two passages. Yet with one line of $\mathrm{HeLa}$ cells DI particles were not apparent even after 200 passages (Stark and Kennedy, 1978). This phenomenon is not due to differences in the ability of the two cell lines to support the multiplication of DI particles (or standard virus). Perhaps some feature of the cytoplasmic architecture of the RNA-synthesizing apparatus or some host-coded component of the polymerase plays a role in determining DI-particle genesis. 
Two other aspects of DI-particle genesis are worthy of consideration. First, it is not clear if the several discrete sizes of DI RNA seen during serial passaging of the alphaviruses constitute the only species of DI RNA capable of being generated. It is possible that a larger spectrum of DI RNAs can be generated but because of size and/or sequence constraints (for example, during packaging) only a few discrete sizes survive to be extensively amplified during successive cycles of virus multiplication. Second, one can ask if in DI RNA any microsequence heterogeneity exists around the junction region between conserved parts of the progenitor. Recently an answer to this question has been obtained for poliovirus DI RNA. Using RNA-RNA duplex mapping, a number of hybrid molecules formed between poliovirus DI RNA and standard negative-strand RNA were examined. These studies showed that both the extent and position of the deletion in DI RNA was somewhat variable (Nomoto et al., 1978). This in turn indicates that deletion may not involve recognition of a specific sequence of only a few nucleotides but rather a region delimiting some feature of secondary structure, for example, a hairpin loop.

\section{ROLE OF DI PARTICLES IN LONG-TERM VIRAL PERSISTENCE}

\subsection{Negative-Strand Viruses}

\subsubsection{Persistent Infections by Enveloped RNA Viruses Other Than Rhabdoviruses}

Persistent infections have been established with many different virus groups (Walker, 1964; Rima and Martin, 1977), and several hypotheses have been advanced to account for this persistence. These include reverse transcription and integration of the viral genome into the host-cell DNA (Zhdanov, 1975; Simpson and Iinuma, 1975), temperature sensitivity of the virus (Preble and Youngner, 1975), and the presence of DI particles (Huang and Baltimore, 1970). This chapter will limit itself to the involvement of DI particles in persistent infection. (See Chapter 2 for a review of the role of temperature sensitive mutants.)

Relatively few persistent infections have been closely examined for the presence of DI particles. However, there are a number of cases where the investigators have not studied DI particles directly, but report evidence that may suggest their presence. Several criteria for their possible involvement are (1) all or at least a large majority of the 
cells in the carrier culture contain viral antigen; (2) carrier cultures are resistant to challenge by homologous virus but support normal replication of heterologous virus; and (3) the virus shed by the carrier culture shows highly reduced infectivity to particle ratio and shows strong interference with infectious virus. Studies which suggest the possible presence of DI particles by more than one of the above criteria include persistent infections by lymphocytic choriomeningitis (LCM) virus (Trowbridge and Pfau, 1970; Lehmann-Grube et al., 1969; Staneck et al., 1972), measles virus (Wild and Dugre, 1978), and Sendai virus (Kimura et al., 1975; Nishiyama et al., 1976). Stronger evidence for the involvement of DI particles in persistent infection is provided by the following studies where the investigators have characterized the persistently infected cultures with regard to the presence of DI particles.

\subsection{1a. Arenaviruses}

Persistent infection of $\mathrm{L}$ cells by $\mathrm{LCM}$ virus has been established (Welsh and Pfau, 1972) and has been shown to produce little if any infectious virus after 50-60 cell divisions, although virtually all the cells contain viral antigen by immunofluorescence. These persistently infected cultures contain a component that specifically interferes with LCM virus plaque formation. The interfering component further characterized by Welsh et al. (1972) closely resembles DI particles. This component does not replicate in the absence of standard virus, and it appears to contain the same viral proteins since LCM immune serum reduces the interfering activity. It is also more resistant to $U V$ inactivation than standard virus, suggesting that it may contain a subgenomic portion of the standard virus RNA.

Persistent infection of BHK cells by LCM virus was examined by Stanwick and Kirk (1976). After 21 passages of the persistently infected cells, infectious virus could no longer be detected by inoculation into mice. However, $90 \%$ of the cells showed presence of viral antigen, and the cultures continued to produce LCM virus particles which protected mice from subsequent intracranial challenge by infectious LCM virus. These interfering particles have not been further characterized but may well be defective. Staneck and Pfau (1974) have reported that a persistent infection established in BHK cells by another arenavirus, Parana virus, also shares many of the properties of other DI-particlemediated systems, including resistance to homologus but not heterologous superinfection and the shedding of an interfering component which has a smaller target to UV inactivation than the infectious virus. 
Recently, Welsh and Oldstone (1977) have characterized L cells persistently infected with LCM virus and showed that early after acute infection LCM antigens were expressed at the cell surface; these cells were efficiently lysed by complement plus antibody and by LCMimmune $T$ cells. After several days, however, strongly interfering DI arose and cell surface expression of viral antigens greatly decreased so that immune $T$ cells were less effective in causing lysis and antibody plus complement was ineffective. However, nearly all cells showed high intracellular levels of virus antigen and continued to do so throughout ensuing weeks of persistent infection despite a continuing suppression of viral surface antigen expression. The authors concluded that DI particles caused reduced surface antigen expression which may allow cells to escape immune surveillance during persistent infection. They found no evidence for $t s$ mutants in LCM persistence.

\subsection{1b. Paramyxoviruses}

Rima et al. (1977) established persistent infections of Vero cells by the Edmonston strain of measles virus. Persistent infection was readily obtained only with inocula which has been passaged serially without dilution. They showed that the infectivity-to-hemagglutinin ratio decreases in the undiluted passage stocks and that the interfering ability increases. The interfering activity was sensitive to UV inactivation and was sedimentable by ultracentrifugation. No accumulation of $t s$ mutations could be demonstrated in undiluted passage stocks. When a sixth undiluted passage capable of establishing persistent infection was passed twice at limiting dilution or plaque purified, it lost the ability to establish persistent infection. Such undiluted passages of measles virus have been shown to cause an accumulation of defective interfering particles containing an encapsidated RNA smaller than the 52 S RNA contained in the infectious particle (Hall et al., 1974). Similarly, after infection of Vero cells with undiluted-passage measles virus, Kiley et al. (1974) have demonstrated the presence of intracellular viral nucleocapsids of small size $(110 \mathrm{~S})$ along with the full size nucleocapsid (200 S). $200 \mathrm{~S}$ nucleocapsids alone were detected in cells infected with the original plaque-purified virus.

Holland et al. (1976c) have also reported establishing a persistent infection of HeLa cells with undiluted passages of measles virus. In the same way they have established persistent infections of BHK cells with mumps and influenza virus. In contrast, the original viral stocks were highly cytopathic and led to the destruction of the infected monolayers. 
However, infection by the virus from fifth undiluted passages led to survival of these cultures, and these became carrier cultures which survived for months. In view of the recent characterization of influenza DI particles by Nayak et al. (1978), it seems likely that the DI particles of influenza virus play a role in persistent infection similar to that which has been described for other systems. Nayak et al. (1978) and Nakajima et al. (1978) observed very small RNA species in influenza DI-particle preparations. These apparently represent genome deletion mutants for various genome segments.

Persistent infection of BHK cells by Sendai virus has recently been established by mixed infection of standard and DI virus stocks (Roux and Holland, 1979). As in all the persistent infections discussed so far, the majority of the cells contained viral antigen and were resistant to superinfection by homologous but not heterologous virus. Characterization of intracellular nucleocapsids showed the continual synthesis of two size classes of viral nucleocapsid RNA: a genome-size 50 S RNA and a smaller size class. When persistent infection was established by infecting the cells with a stock of standard virus alone and selecting for the few surviving cells, both standard virus and DI-article-size classes of intracellular viral nucleocapsid RNA were observed. This appears to be a result of amplification of a DI particle known to be present in this standard virus stock (Kolakofsky, 1979). The contaminating DI particles were probably responsible for the survival of a few cells after standard virus infection. In both cultures Roux and Holland consistently observed a ten- to hundredfold greater amount of the smaller size class RNA compared to $50 \mathrm{~S}$ RNA after 24-hr labeling. On day-to-day analysis no overall change in the ratio of DI to standard RNA synthesis could be observed (Roux and Holland, 1980). However, the composition of the DI size class of RNA varied constantly: some species of DI RNA disappeared and others appeared with continued passage of the persistently infected cells. No selection toward a particular size class RNA was observed during the 12-month period of analysis. Interestingly, challenge infection of these carriers with standard virus either caused no change in nucleocapsid RNA ratios or stimulated synthesis of more molecules of DI RNA than of standard virus RNA.

\subsubsection{Persistent Infection by Rhabdoviruses}

Wagner et al. (1963) were the first to establish persistent rhabdovirus infections with VSV in cultured L cells, and they showed clearly that small-plaque mutants were greatly favored in their ability 
to establish persistence. Holland and Villarreal (1974) showed the DI particles were essential for establishment of persistent infection, along with $t s$ mutant infectious virus of VSV. These persistently infected carrier cells continuously shed low levels of infectious virus and DI particles. DI particles recovered from these carrier cells were able to reestablish persistent infection of BHK21 cells when coinfected with either wild-type or $t s$ mutant infectious virus, whereas the "wild-type DI particle" originally employed could help establish persistence only with the group III (matrix protein) mutant $t s$ G31. This original BHK21VSV Indiana carrier (abbreviated herafter as CAR4) has now been maintained for over 6 years as a persistently infected carrier culture and has been extensively characterized. It has shed only low levels of mature virus and DI particles even though all or nearly all cells are continuously infected, grow at near-normal rates, and exhibit large amounts of virus antigen in the cytoplasm. Large amounts of biologically active DI RNP can be recovered from the cytoplasm of disrupted cells, and these will reinitiate persistent infection when coinfecting with infectious virus. Shed virus is temperature sensitive, and all isolates are very slow growing small-plaque mutants at any temperature. However, these cannot reinitiate persistent infection of BHK21 cells at any multiplicity without addition of DI particles to attenuate cytopathic effects. It appears that intracellular DI nucleocapsids suppress viral RNA synthesis to such low levels at any temperature that cells maintain nearly normal cell synthesis and growth (Villarreal and Holland, 1976). No evidence for a role of interferon or for integrated DNA copies of viral RNA could be obtained.

Another rhabdovirus, rabies virus, is notably different from VSV in causing generally less cytopathology in cultured cells and in the relative ease with which it establishes persistent infections in vitro (Fernandes et al., 1964). Wiktor and Clark (1972) characterized hamster cells and other cells chronically infected with rabies virus and observed cyclic variations in titers of infectious virus shed by carrier cultures. They concluded that interferon might be regulating these fluctuations in yield. Kawai et al. (1975) established BHK21 rabies virus carrier cultures and showed that the cyclic variations in virus yield correlated with cyclic patterns of rising and falling levels of rabies virus DI particles. These cyclical patterns of virus and DI-particle production were strikingly similar to the cyclic rising and falling of VSV virus and DI particle production which occurs when fresh uninfected cells are added regularly to cultures infected with VSV (Palma and Huang, 1974). Furthermore, no interferon could be detected or induced in the 
persistently infected BHK21 cells of Kawai et al. (1975), and these carrier cells were resistant to homologous rabies virus challenge but fully susceptible to heterologous challenge by VSV. Small-plaque, slightly $t s$ mutants arose in these carrier cultures and eventually displaced wildtype infectious virus. These cloned small-plaque mutant viruses caused greater cytopathology than wild-type virus and could not by themselves induce persistent infection. These small-plaque mutants generate both interfering and noninterfering defective particles (Kawai and Matsumoto, 1977). Strangely, the rabies small-plaque mutants were resistant to homologous interference caused by the DI particles generated by large-plaque, wild-type HEP rabies virus. However, the DI particles which they generated interfered with both large-plaque wildtype HEP Flury rabies virus and with the small-plaque mutant virus which generated them. Obviously, this specificity of DI interference could play a role in selection of virus mutants surviving during persistence. In much less thorough studies of rabies persistence, Holland et al. (1976c) have also implicated DI-particle involvement, and greatly reduced levels of rabies virus directed RNA synthesis (Villarreal and Holland, 1976).

The most extensively studied carrier system is that of VSV in BHK21 cells (Holland and Villarreal, 1974; Holland et al., 1976c, 1978). Studies of this persistently infected culture over a period of 5 years have shown that DI particles and their nucleocapsids play a critical role in the establishment and the maintenance of long-term persistence. In sharp contrast to this system where the role of DI particles is clear, a variety of L-cell-VSV carriers have been described where other factors (including or excluding the presence of DI particles) are implicated. The L-cell-VSV carrier cells of Youngner et al. (1976) appear not to involve DI particles but strongly involve viral mutation to temperature sensitivity (see also the chapter by Youngner and Preble in this volume). Ramseur and Friedman (1977) also implicated $t s$ mutants and showed a role of interferon in establishing persistence in L cells and perhaps in maintaining it. They also showed that high levels of anti-IF could terminate this chronic infection. Nishiyama (1977) implicated $t s$ small-plaque mutants, DI particles, and interferon as being involved in his L cells persistently infected with VSV. He also found that only $5-30 \%$ of cells showed viral antigens, and he showed that treatment with antiviral antibody led to curing of the carrier cells. As with the carrier cells of Ramseur and Friedman (1977), the involvement of interferon was reflected in the ability of these cells to resist heterologous challenge by Mengo virus or EMC virus (as well as resistance to homologous VSV 
challenge). Stanners et al. (1977) have reported that a $t$ s mutant (T1026) of VSV able to establish persistence in cells is a double mutant affecting RNA polymerase activity and shutoff of protein synthesis. Finally, Nishiyama et al. (1978) have characterized ts small-plaque mutants recovered from persistently infected $L$ cells and showed that these were better inducers of interferon than wild-type VSV, and they are also more sensitive to the action of exogenous interferon and can initiate persistence without added interferon when infecting $\mathrm{L}$ cells at low multiplicity of infection. Holland et al. $(1976 b, c)$ observed high levels of DI particles produced by L cells persistently infected by VSV plus DI particles, but these never gave long-term persistence and despite numerous attempts these carriers spontaneously cured within several weeks or several months as was observed by Ramseur and Friedman (1977).

Clearly, L-cell VSV carriers can involve a number of factors; DI particles may be involved in some of these persistent infections and not in others. This is in sharp contrast to the BHK21-VSV and BHK21rabies carriers described above in which DI particles play an essential and continuing role. Recently, we reported a HeLa cell line which replicates VSV DI particles very poorly at times or not at all at other times (Holland et al., 1976a). We have utilized this HeLa cell line in an attempt to analyze VSV persistence in the absence of DI particles. One persistently infected VSV carrier culture established with these HeLa cells shed DI particles (apparently due to selection of DI-particle-producing cells) (Holland et al., 1976a). Another VSV-HeLa cell carrier designated CAR49 (Holland et al., 1978) shed VSV for nearly 1 year until it cured spontaneously. At no time did this carrier shed detectable DI particles. This allowed critical comparison of this type of culture with the DI-particle-producing type. Table 1 compares and contrasts what is known about the DI-particle-producing rhabdovirus-persistent infections (e.g., BHK21-VSV or BHK21-rabies) with those which do not (or need not) involve DI particles (e.g., HeLa-VSV-CAR49 and LCell-VSV carriers).

It can be seen in Table 1 that there are many distinguishing characteristics between the type of persistent infection involving DI particles and those not involving DI particles. The most striking difference lies in the fact that all or nearly all cells are infected at all times in the DI-particle-producing carrier cells, whereas only a small percentage of cells are usually infected and exhibiting virus antigen in the DI-particle-negative carrier cells. The ease with which these latter carriers are cured by antibody treatment suggests that these carrier cultures lacking DI particles are persistently infected only at the popula- 


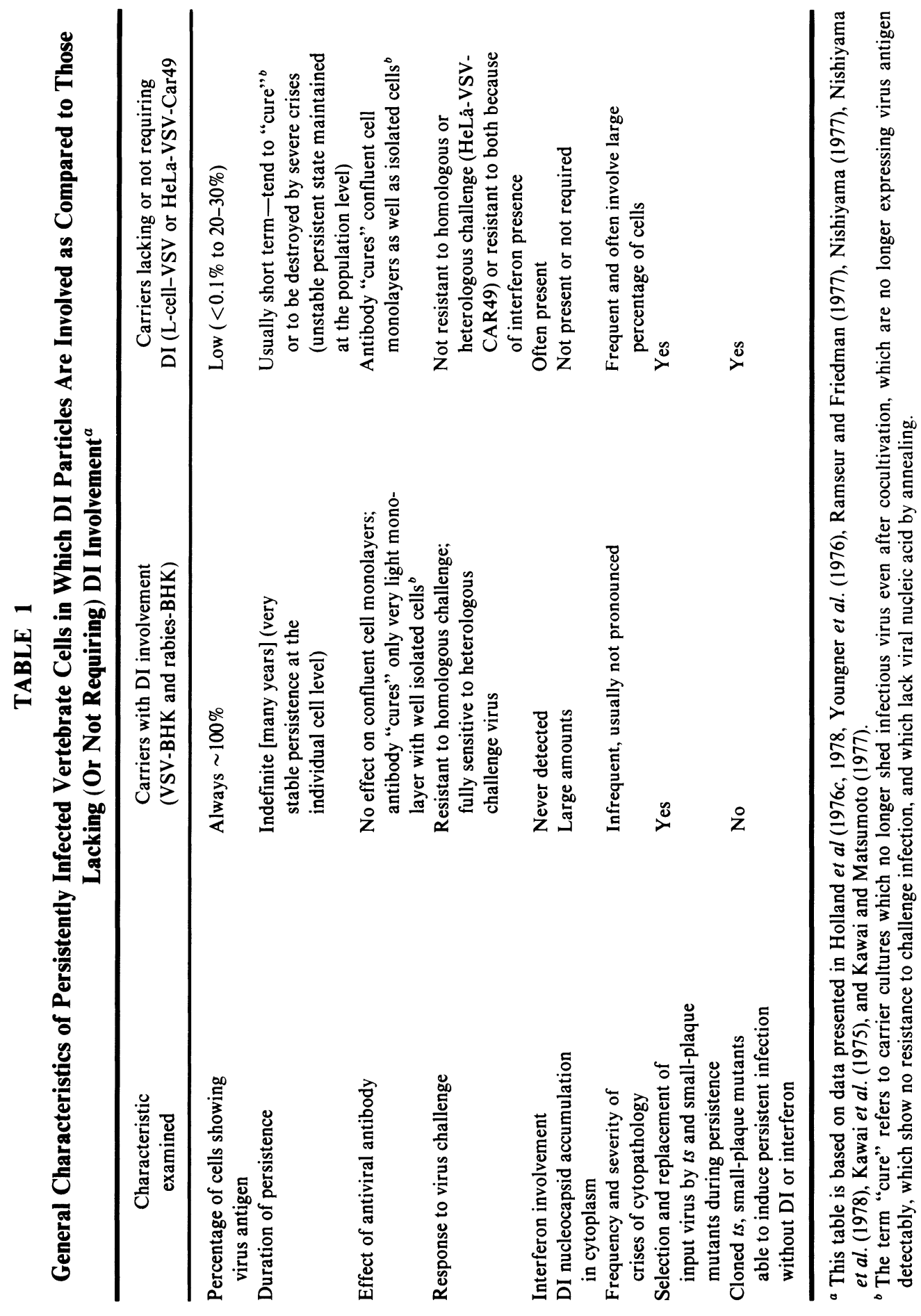


tion level so that immune isolation of cells from each other leads to rapid curing. In contrast, the buildup of interfering DI nucleocapsids in the cytoplasm of cells of the DI-particle-mediated carrier state (Holland et al., 1976c; Roux and Holland, 1979) can allow slow noncytocidal replication of virus within cells for months or years in the presence of antiviral antibody (Holland et al., 1976c) and even within carrier cells transplanted into nude mice for months or years (Reid et al., 1979, and see below).

In vivo cell surface antigenic modulation by antibody as well as by DI particles may be required to prevent lysis of persistently infected cells by antibody plus complement or by immunocytes (Joseph and Oldstone, 1975). Whether persistent infections of the non-DI-particleproducing type can survive for months or years in vivo in intact animals remains to be established. Perhaps this type might be maintained better in cases where there is extreme immunological deficit (whether virus antigen specific or nonspecific). However, it is well established that persistent RNA virus disease can occur in the absence of general or virus antigen-specific immunodeficiency (Welsh and Oldstone, 1977; Perrin et al., 1977).

The distinguishing characteristics delineating DI-particle-positive and DI-particle-negative persistent infections (listed in Table 1) may prove generally useful as an indicator of the factors involved in any particular in vitro persistent infection by enveloped RNA viruses. Determination of such parameters in vivo will be much more difficult. Note in Table 1 that both types of carrier culture share one very important common characteristic: in both types of persistence there is strong selection of $t s$ and small-plaque mutants. Slow-growing smallplaque mutants nearly always appear even when the mutant virus is not $t s$ (or is only slightly $t s$ ). These mutants are often lower in polymerase activity and more sensitive to interferon and induce interferon more efficiently (see above). All of these phenotypic characteristics of mutant virus from persistent infection could be explained by a single unifying hypothesis: namely, that multiple mutations occur in the genome of viruses during persistence. This hypothesis has been confirmed by $T_{1}$ ribonuclease oligonucleotide mapping of VSV infectious virus recovered from BHK21-CAR4 carrier cells persistently infected for more than 5 years (Holland et al., 1978, 1979). Beginning within 1 year and continuing thereafter beyond 5 years, the original cloned input virus has undergone massive and continuing genome rearrangement which probably represents dozens or even hundreds of mutations. Figure 5 shows the $T_{1}$ RNAse oligonucleotide differences between the original 

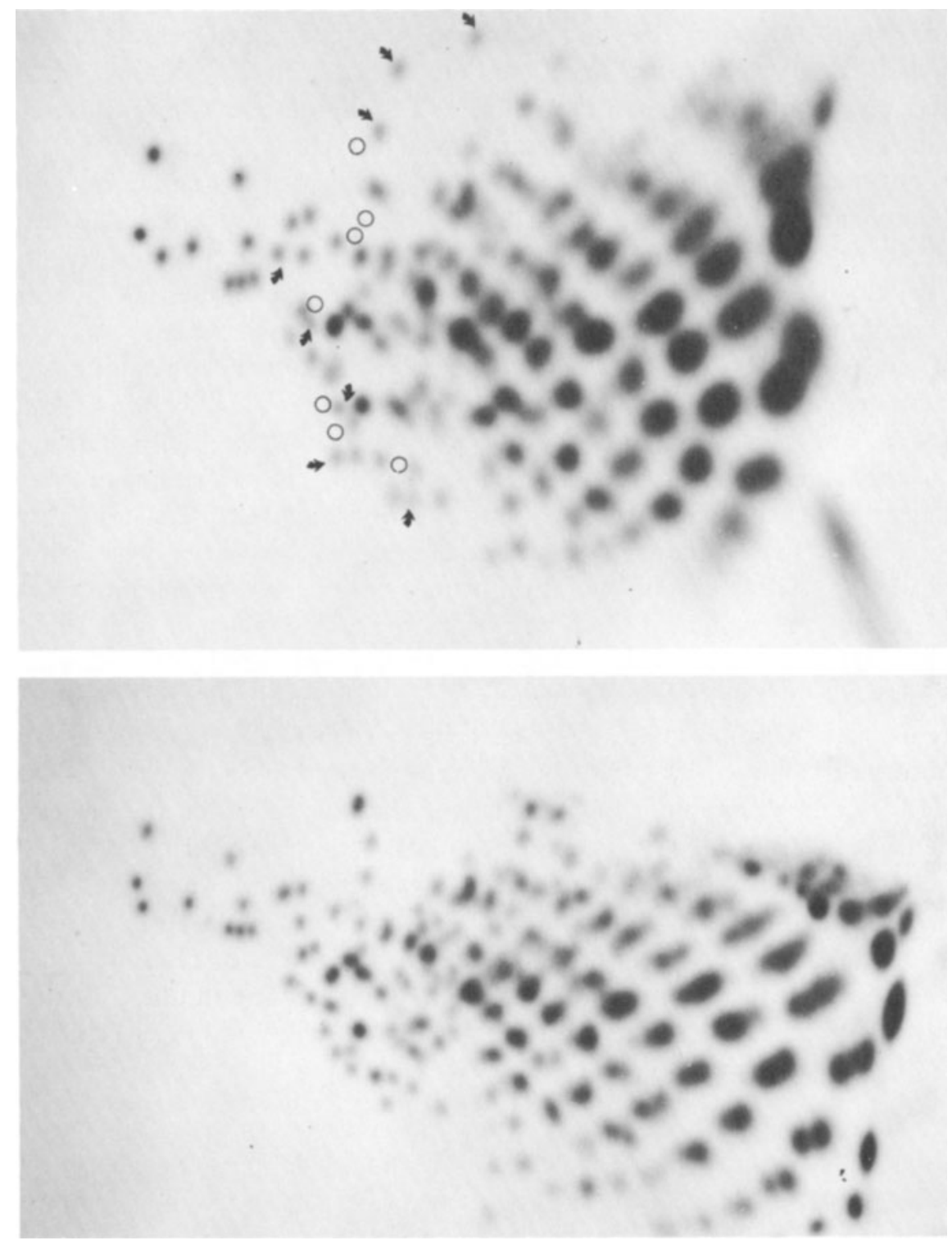

Fig. 5. Ribonuclease Tl oligonucleotide map. Comparison of the genome RNA of the original clone of vesicular stomatitis virus used to establish persistent infection of BHK21 cells (bottom panel) with the genome RNA of a clone of small-plaque $t s$ mutant recovered from the BHK21-VSV-Ind-CAR4 carrier cells after 5 years of persistent infection at $37^{\circ} \mathrm{C}$ (top panel). The arrows indicate new oligonucleotides which have appeared and the circles indicate where oligonucleotide spots have disappeared during 5 years of persistent infection. 
virus and the small-plaque $t s$ mutants recovered after 5 years of persistent infection. Peptide mapping studies in progress (Holland, unpublished) also show significant alterations in the proteins of the recovered small-plaque mutants. These small-plaque, slowly growing mutants do not readily undergo reversion either phenotypically or genotypically (Holland et al., 1979). While the virus genome is accumulating these massive mutations, the DI population recoverable from persistently infected cells is constantly changing, with newly arising DI particles replacing previous DI particles. Since numerous genome mutations do not accumulate on repeated lytic passage of VSV (Clewley et al., 1977; Holland et al., 1979), it appears that long-term persistent infection selects for massive mutation within the virus population, and persistence may well be important in the rapid evolution of enveloped RNA virus genomes. This possibility is particularly intriguing with regard to antigenic variants of influenza virus. Persistent Visna virus infection is known to give rise to antigenic variants (Narayan et al., 1977). A less drastic evolution of measles virus $M$ protein may take place during prolonged CNS infection in SSPE (Wechsler and Fields, 1978; Hall et al., 1978). However, Hall et al. (1979) found electrophoretic differences in $M$ protein among different strains of measles virus, but with no pattern characteristic of SSPE strains. They did observe a relative lack of antibodies to $M$ protein in SSPE patients.

Whether changing DI particle populations influence the selection of multiply mutant virus genomes is not clear (Holland et al., 1979), but the DI specificity observed for rabies mutants by Kawai and Matsumoto (1977) is suggestive in this regard. However, in HeLa-cell DIfree carriers of VSV, multiple mutations accumulate (Holland et al., 1979), and at least some mutations must be occurring in other non-DIparticle-producing carrier states (e.g., Youngner et al., 1976; Mudd et al., 1973).

\subsection{Positive-Strand Viruses}

Togaviruses, picornaviruses, and reoviruses are usually cytocidal for vertebrate cells in tissue culture. Persistently infected cultures are therefore often difficult to establish; we are aware of only a single report of a picornavirus persistent infection in cell culture (Crowell and Syverton, 1961). In contrast, there is accumulating evidence of picornavirus persistent infection in human patients suffering from agamma- 
globulinemia (Wilfert et al., 1977); the picornavirus system is therefore worthy of further study. For the alphaviruses, both Western encephalitis virus and SV have been established in a persistent state in L cells (Chambers, 1957; Inglot et al., 1973). Persistent infection of BHK cells with SV (Weiss, et al., 1980) and SFV has also been initiated. Persistent infection of rabbit kidney cells with Japanese encephalitis virus has been reported (Schmaljohn and Blair, 1977). Alphaviruses (and flaviviruses) readily establish persistent infections in cultured invertebrate cells (Rahacek, 1968; Peleg, 1969; Stollar and Shenk, 1973). These systems are of considerable interest because of the natural transmission cycle of togaviruses from vertebrates through insects and back to vertebrates. L cells, CHO cells, and Vero cells have been employed to study reovirus persistence in culture (Taber et al., 1976; Ahmed and Graham, 1977). Reovirus has also been employed to study persistence in small rodents (Graham, 1977).

At the present time the evidence for the involvement of DI particles in togavirus persistent infection in vertebrate cells in cultures is accumulating. Inglot et al. (1973) suggested that DI particles of SV may play a role in persistent L-cell infection. These authors also pointed to the involvement of interferon in this system. Recent data also indicate that, for SFV, interferon plays a major role in maintaining the persistent state in L cells and that DI particles are not involved in maintenance, although they do greatly facilitate the establishment of the carrier state (Meinkoth and Kennedy, 1979). In BHK cells on the other hand, DI particles are indispensible in establishing persistence, and at all times examined (over 3 years) the carrier culture contains substantial amounts of DI particles. Interferon appears to play little or no role in this system. Persistence in cultures of rabbit kidney cells and Vero cells could readily be established by the flavivirus Japanese encephalitis virus (Schmaljohn and Blair, 1977). In this study only serial undiluted passage fluid could establish the persistent infection in the rabbit cells, and culture fluid from these cells was used to establish the carrier state in Vero cells. The virus produced from the rabbit cells was tentatively identified as containing DI particles. Although these observations are indicative of a role for DI particles in both the establishment and the maintenance of the carrier state, final proof awaits additional experimentation.

Considerable effort has been invested in evaluating the role of DI particles in alphavirus persistence in invertebrate cells, notably in the Aedes albopictus cell line. In contrast to the vertebrate cell, persistent infection in the mosquito cell can readily be established with standard virus alone (Stollar and Shenk, 1973; Davey and Dalgarno, 1974; Iga- 
rashi et al., 1977; Eaton, 1977). In these studies infection resulted in rapid multiplication of virus followed after about 4-6 days by a decline in virus yield which lasted several weeks and which culminated in a plateau level of virus production. This level remained constant for as long as the cultures were maintained. Although suggested by earlier studies (Stollar and Shenk, 1973), it has only recently become clear that persistently infected mosquito cells produce DI particles. Igarashi $\boldsymbol{e t}$ al. (1977) presented evidence that double-stranded RNA characteristic of replicative form derived from DI RI RNA (see preceding section) was formed in SV persistently infected mosquito cells by 10 weeks after infection. Eaton (1977) showed that the pattern of RNA synthesis in BHK cells infected with culture fluid from SV persistently infected mosquito cells was characteristic of infection with stocks containing DI particles and concluded that the persistently infected cells were releasing DI particles into the extracellular medium. Thus there is now evidence that cultured mosquito cells can produce DI particles. It is premature at this time, however, to implicate DI particles in any essential role in maintaining the carrier state.

The studies of Ahmed and Graham (1977) have pointed to the importance of DI particles in persistent reovirus infection in L cells and Vero cells. Passages of reovirus rich in DI particles which were extensively deleted in the $L_{1}, L_{3}$, and $M_{1}$ segments of the genome (see earlier) could readily initiiate persistence. The greater the proportion of DI particles in the inoculum, the greater was the capacity of the virus stock to initiate persistence. By contrast, DI-particle-free stocks were unable to initate persistence, and the infected cultures perished. About $80 \%$ of the cells in the persistent state continuously produced virus, and in this system frequent crises were observed. Analysis of the carrier cultures during the first 18 passages showed that defective particles were always present. However, the status of these particles as true interfering DI particles was not demonstrated; therefore, the role of DI interference in maintaining the carrier state was and indeed remains unclear. One additional feature of these studies was that, although persistence was established using a $t s$ mutant of the standard virus, the phenotype of the standard virus isolated from the carrier culture was that of wild type. This situation is in contrast to many other virus-carrier states where evolution of $t s$ mutants occurs (e.g., Preble and Youngner, 1975; Younger et al., 1976; Youngner and Quagliana, 1975). Thus for reovirus there is compelling evidence for a role for DI-like particles in establishing persistence in vitro (and also in vivo-see below). The role of DI virus in maintaining the carrier state is less clear. 


\subsection{In Vivo Evidence for DI-Particle Protection}

Since DI particles are able to interfere with the growth of standard virus in cell culture, their ability to affect the outcome of infection in animals is of particular interest. DI particles clearly can be generated and replicated in vivo. The first characterization of DI particles was carried out "in vivo" with influenza in eggs (von Magnus, 1951). Sendai virus (Kingsbury et al., 1970) also was shown to generate large quantities of DI particles in eggs. However, the chorioallantoic membrane of embryonated eggs, where most virus replicates, in many respects more closely resembles a cell culture monolayer than a whole animal. However, recent studies demonstrate that DI particles can also be generated in vivo in animals. VSV generates DI particles more readily in baby mice than in adults (Holland and Villarreal, 1975). DI particles have also been found to be generated intracerebrally by rabies virus in baby mice (Holland and Villarreal, 1975), by Rift Valley fever virus in mice (Mims, 1956), and by LCM virus in mice (Popescu and LehmannGrube, 1977).

To determine whether interference by DI particles could prevent viral disease, von Magnus (1954) attempted to protect mice against challenge with influenza virus by use of a high-passage virus stock containing large numbers of DI particles; he obtained fewer deaths and reduced virus multiplication compared to controls. Similar experiments by Holland and Doyle (1973) with influenza virus and VSV showed an inhibition of virus multiplication but no significant protection. However, subsequent work with VSV indicated that these early failures were probably due to contaminating infectious virions in the DI particle preparation and probably also to DI particles in the standard virus preparation. In more careful studies in which large numbers of highly purified VSV DI particles (completely freed of infectious virus) were injected into mice along with a low but otherwise lethal challenge dose of standard virus, the purified DI particles provided complete prophylaxis (Doyle and Holland, 1973). As the dosage of challenge virus was increased, fewer mice survived. However, those that died succumbed after a lengthened course of disease and exhibited a different syndrome as compared to control animals. Crick and Brown (1977) in a follow-up study concluded that the protective effect of DI might be due to the immunizing capacity of inactivated DI since chemically inactivated infectious virus provides good immunization when given 2 days before the challenge. Also, they observed some homologous and heterologous prophylactic effect when inactivated DI particles were injected 
simultaneously with challenge virus. These effects were quantitated as shifts in $\mathrm{LD}_{50}$ (i.e., by summing results at different challenge doses and averaging results).

Recently, Jones and Holland (1980) have examined this approach using UV-inactivated DI particles (and UV-inactivated standard virus as control). In these experiments they employed low challenge virus dosages given simultaneously with, or 3 days subsequent to, DI-particle administration. No prophylactic protection from death was obtained with any UV-inactivated standard virus or UV-inactivated DI particle, whereas noninactivated DI particles gave strong prophylactic protection. However, in agreement with the data of Crick and Brown (1977) on nonspecific protection, it was observed that UV-inactivated snapback DI particles (i.e., those containing covalently linked plus and minus RNA) did prolong the life of animals challenged simultaneously with standard virus (but failed to protect them from death). However, UV-inactivated non-snap-back DI particles gave no effect when administered simultaneously with challenge. These effects may be attributable to interferon induction. A similar induction of interferon by the DI particles employed by Crick and Brown could explain the slight nonspecific protection they observed since "snap-back DI particles" are rather common (Perrault and Leavitt, 1977a) and since they are known to be powerful inducers of interferon (Marcus and Sekellick, 1977). We conclude that prophylactic protection of mice by VSV DI particles requires replicating and interfering ability and is due to true homologous interference. Additional factors such as interferon induction and antigenic immunization may also play a role in protection. Dimmock and Kennedy (1978) reached similar conclusions for DI protection against SFV. They observed that the DI particles must be inoculated into mice slightly before or concurrently with the challenge virus to obtain prophylactic protection. As with VSV, DI particles provided protection from a normally fatal dosage of SFV; however, in this system there was no alteration of the disease syndrome in the presence of DI particles. Another system in which DI particles were shown to provide protection is the infection of 2-day-old rats with reovirus (Spandidos and Graham, 1976). Additionally, in this system a very high percentage of the surviving animals was affected by a severe runting syndrome; these animals chronically shed virus and DI particles. In addition to their ability to prevent disease or to alter its course, DI particles may be involved in altering virus-cell interactions with the immune system as cited above. Welsh and Oldstone (1977) and Huang et al. (1978) have also shown reduced virus antigen expression on the 
surface of infected cells coinfected with DI; this results in reduced susceptability to immune attack.

Rabies DI particles were shown by Wiktor et al. (1977) to have some protective effect against intracerebrally inoculated (but not against peripherally inoculated) challenge virus. However, Wunner and Clark (1978) were unable to ascribe a protective role to rabies DI particles in comparisons of virus stocks containing DI particles when these were titrated intracerebrally in mice. Obviously, more work is needed to determine whether DI particles are protective in rabies virus infections.

As one would expect, the large dosages of DI particles necessary to give protection are immunogenic (Doyle and Holland, 1973), and a protective immune response was seen after 3 or more days even with inactivated DI particles which are capable of protection against concomitant challenge. Large numbers of DI particles were necessary for prophylaxis with VSV, SFV, and reovirus. Minimum effective numbers of VSV DI particles were at least $10^{8}$ per mouse, while $10^{7}$ generally were necessary for SFV and reovirus. Since the lethal dose of standard virus in these systems can probably be produced by the yield from one infected cell, effective prophylaxis requires that DI particles must coinfect every cell initially infected by standard virus. This could explain the dependence on large numbers of DI particles.

Finally, Faulkner et al. (1979) have employed dissociated neuron cultures from mice to study the neuronal role of VSV DI particles. Standard virus alone replicated to high levels selectively in neuronal (as compared to nonneuronal CNS cells) and caused cell death within 1-2 days. Coinfection with large amounts of DI particles completely suppressed virus replication and greatly delayed neuronal cell death. This is strong evidence that true DI-particle interference can take place in CNS neurons.

\subsection{In Vivo Evidence for DI-Particle Persistence}

When LCM virus was studied in vivo in mice using a sensitive interference focus assay for DI particles, DI particles were found in the organs of both acutely infected adults and in carrier mice which were infected neonatally (Popescu and Lehmann-Grube, 1977). The ratio of DI particles to infectious virions differed in various organs; these ratios declined with time in the carrier mice. These observations in vivo appear to correlate with the variation in the ability of different cell cul- 
ture lines to support DI particle replication and with the relative ease of generating VSV DI particles in baby mice vs. adult mice. Welsh and Oldstone (1977) have recently provided evidence that peritoneal macrophages of LCM carrier mice contain DI particles, and Welsh et al. (1977) have recently demonstrated that DI particles of LCM virus can provide strong protection against cerebellar LCM disease and LCM virus antigen expression in baby rats coinfected with LCM virus homologous DI particles. Coupled with the finding of LCM virus DI particles in many tissues of persistenty infected mice (Popescu and Lehmann-Grube, 1977), these results suggest a likely involvement of DI particles in acute and persistent LCM virus infections in vivo.

DI particles also play an important role in persistent infections of newborn rats with reovirus (Spandidos and Graham, 1976; Graham, 1977). When infected intracerebrally with DI-particle-free stocks, all the rats died within 12-14 days. However, when the inoculum contained DI particles, over $60 \%$ of the rats survived and developed the usual runting syndrome of a chronic infection. Defective virus (not shown to be interfering) was detected in the brain of a runted rat 24-30 days after infection. It has also been shown in vivo that the tumorigenicity of established cultured tumor cell lines is strikingly abrogated by persistent infection with enveloped RNA viruses (Yamada and Hatano, 1972; Reid et al. 1979). This suppression of tumorigenicity of BHK 21 cells by DI-particle-mediated persistent VSV infection in nude mice is due to natural killer lymphocytes (Minato et al., 1979). These natural killer cells are not only capable of killing the persistently infected cells with greater efficiency than they kill uninfected cells but also appear to be more efficiently induced by infected cells. These natural killer cells are strongly activated by interferon. This induction of interferon could in turn be due to the snap-back class of DI particles (Marcus and Sekellick, 1977). Moreover, Ito et al. (1975) have shown that Sendai persistently infected cells can induce interferon.

This ability to maintain persistently infected tumor cells in vitro offers an ideal tool for in vivo study of persistence. We have found that DI and virus function in vivo in these cells in a manner similar to in vitro VSV persistence (Reid et al., 1979) and biologically altered virus mutants can be selected when persistently infected cells able to escape the natural killer cell response are selected (Reid et al., 1979; Minato et al., 1979). These nude mouse persistence models should lead to significant insight into in vivo parameters of persistence. Little is known about long-term in vivo persistence at present, although Wagner (1974) and Stanners and Goldberg (1975) showed that $t s$ mutants injected into 
animals give an altered disease process with reduced death rate and prolonged time until death. Rabinowitz et al. (1976) showed that different $t s$ mutants of VSV cause quite different histopathological changes and quite different degrees of virulence. Whether such infections ever lead to long-term persistence and whether DI appear during their course is not yet known.

Similarly, work with class B and C mutants of reovirus type 3 in newborn rats showed that more rats survived inoculation with either mutant type than with the wild-type virus. Also, following inoculation with the class B mutant virus, more of the surviving rats developed the runting syndrome indicative of chronic infection (Fields, 1972). It is of interest that these mutants appear to generate DI particles more readily than the wild-type virus in cell culture (Spandidos et al., 1976).

\section{RECENT PRELIMINARY EVIDENCE FOR DI-PARTICLE INVOLVEMENT IN PERSISTENCE OF DNA VIRUSES}

In contrast to the situation with RNA viruses there has, until very recently, been almost no serious investigation of the possible role of DI particles in persistent infections by DNA viruses. This is understandable since there might appear to be no need for DI particle involvement in persistence of DNA viruses. Viral DNA integration into cell chromosomal DNA offers a simpler, more straightforward, and wellestablished mechanism for DNA virus persistence. Nevertheless, some DNA virus-cell systems may involve a role of DI particles in persistence if some very recent preliminary studies are confirmed and extended.

Norkin (1979) has clearly demonstrated the involvement of DI particles in one type of SV40 virus persistence in monkey cells, with considerable levels of DI particle DNA being present throughout the course of persistent infection. Henry et al. (1979) described conditions for efficient production of DI particles of equine herpesvirus type 1 and alluded to as yet unpublished evidence that they can play a role in establishing persistent infection by this herpesvirus. Likewise, Stinski $e t$ al. (1979) and Mocarski and Stinski (1979) have described the production of DI particle DNA by serial high-multiplicity passages of cytomegalovirus and cite very preliminary evidence for their involvement in establishing persistent infection and their production by persistently infected cells.

It is difficult to see why DI particles and DI genome DNA would 
be necessary or important in persistent infection by herpesviruses, papovaviruses, or other DNA viruses able to integrate their genomes. If they do prove to be important in some types of DNA virus persistence in vitro, it will be interesting to look for their presence and possible involvement in latent and recurrent herpesvirus infections of humans. Stevens (1978) has already shown that replication-defective $t s$ mutants of Herpes simplex virus establish central nervous system persistent infections with high efficiency. Whether DI particles or their subgenomic DNAs also can play a role in natural infections must await sensitive quantitative assays for DI particles of these and other DNA viruses.

It may ultimately be found that integration of complete genomes suffices for persistence in some DNA virus-cell systems, whereas a constantly mutating plasmid state with DI particle interference may prove necessary for others. A smoldering plasmid state with DI cycling and selection of viable multiple mutants of standard virus might offer the same advantages for persistence of DNA viruses that it offers for RNA viruses (more frequent release of infectious virus, selection of viable mutants with ability to break through the immune response occasionally, etc.).

\section{CONCLUSION}

DI particles are clearly able to affect standard virus replication in vitro and in vivo in animals and are clearly involved (along with massive mutational change of the infectious virus) in at least some types of enveloped RNA virus persistence. In at least these complex types of persistence, single point mutations to temperature sensitivity cannot alone explain long-term persistence. Details of the altered interactions between the constantly changing infectious virus population with selection of massive mutational change and the constantly changing DI population remain to be clarified.

The reasons for DI particle presence in some types of vertebrate cell-virus persistence and not in other types are not clear as yet. There are some obvious correlations: (1) The most highly susceptible cells which produce the highest yields of infectious virus generally tend to generate and replicate DI particles more efficiently than do less susceptible cell types; (2) these high-virus-producing, high-DI-particle-producing cell types generally tend to produce more stable persistent infections (Holland et al., 1976c, 1978) in which nearly $100 \%$ of the cells are 
usually involved and in which DI particles are present. In contrast, less susceptible lines which are poor DI-particle producers more often tend to initiate less stable, non-DI-particle-producing carrier states at the cell population level. In this case a low percentage of cells are infected at any given time and total destruction of the population is avoided through the antiviral effect of interferon and/or by attenuation of the virus. Spontaneous cell curing by unknown mechanisms may affect the balance between infected and uninfected cells.

Insect cells such as Drosophila cells in culture represent a unique case in which only very low levels of VSV can be produced (Mudd et al., 1973) and in which we have consistently failed to detect even traces of DI particles. Nevertheless, every VSV infection of these cells invariably leads to long-term persistent infection. The same is true of Aedes albopictus cells infected with VSV (Holland, unpublished data). However, Kennedy (unpublished data) has cloned these $A$. albopictus cells and categorized clonal populations into those which are highly susceptible to SFV, those which are moderately susceptible, and those which replicate virus only to very low levels. The cloned populations producing large amounts of virus also generate and replicate large numbers of DI particles and show continuing production of virus and DI particles during long-term persistence. In contrast, uncloned $A$. albopictus cells and low-producer cloned cell populations produce no DI particles either on initial infection or during prolonged persistence. Perhaps there is a threshold level of virus production below which DI particle production cannot be initiated or maintained and below which DI-particle production is not useful for cell and tissue survival after virus infection. Indeed, it is possible to envisage a class of persistent infection in which the host cell and the infectious virus establish a symbiotic relationship without recourse to either DI-particle modulation of cellular defense. Persistent infection of invertebrates which are devoid of immunosurveillance or possibly even persistent infection of vertebrates for which immunodefense is not available may be examples of such a virus-cell relationship.

Clearly, there is a dearth of knowledge regarding biological mechanisms of DI-particle generation, DI-particle interference, and DIparticle protective effects in tissues and organs of intact animals. Although structural studies of DI RNA and viral RNA allow formulation of some reasonable hypotheses regarding DI-particle generation, replication ,and interference, these studies remain unsupported by hard experimental evidence and probably shall remain so until cell-free viral and DI-particle replication systems are developed. 
Studies of the influences by DI particles on the course of virus infections in intact animals are difficult to assess for a variety of reasons. Among these are (1) the presence of at least low levels of DI particles in most standard virus stocks prior to in vivo inoculation, (2) difficulties in quantitating the presence of small numbers of DI particles in vivo, especially when a vigorous immune response limits replication of infectious virus to low levels, and (3) the need for large numbers of purified DI for in vivo prophylaxis (over $10^{8}$ particles per mouse in the case of VSV). This last problem is particularly troublesome since even this rather small mass of viral antigen might stimulate the immune system and interferon, and complicate interpretation of protective effects. Smaller numbers of DI particles are probably ineffective because they would have a vanishingly low probability of coinfecting one of the few brain cells initially infected by the infectious particles of the low-input inoculum, thereby leading to foci of massive infectious virus production prior to any DI-particle involvement. Obviously, more refined experimental approaches are needed to answer most biological questions regarding DI-particle involvement in natural disease and in virus persistence, but it is already clear that they are ubiquitous and can be involved in vivo both in acute and in persistent infections of certain kinds.

The advent of rapid RNA sequencing, the continuing elucidation of viral defense mechanisms in the whole animal, and the prospect of cell-free viral and DI RNA replication all promise to make the next few years of research into the biology of DI particles and persistence extremely exciting.

\section{Note Added in Proof}

Since this review was written, a number of relevant studies have appeared, and these are briefly cited below.

DI Particle Genome Structure. Perrault and Semler (1979, Proc. Natl. Acad. Sci. USA 76:6191), Clerx-van Haaster et al. (1980, J. Virol. 33:807), and Epstein et al. (1980, J. Virol. 33:818) have now shown that internal deletion is involved in generation of the rare transcribing class of VSV DI particle. Perrault and Semler also confirmed that purified preparations of this transcribing class of DI particle compete very poorly with the standard class DI particles. Also, Schubert et al. (1979) have shown that three different DI particles of the standard class have complementary stems. One of these was 45 and the other two were 48 base pairs 
in length (see page 142, third paragraph, and page 154, second paragraph, for related discussion.)

Obijeski et al. (1980, Nucleic Acids Res. 8:2431) have now shown that the two smallest RNA segments from LaCrosse virus have termini with extensive complementarity.

McClure et al. (1980, Virology 100:408) reported a new type of DI particle of poliovirus and mengovirus with only $4-6 \%$ of the genome deleted, and no detectable density change from that of standard virus.

Rao and Huang (1979, Proc. Natl. Acad. Sci. USA 76:3742) and Leppert et al. (1979, Cell 18:735) have shown synthesis of small RNA copies of DI particle RNA 3' termini in infected cells.

Virus and DI Particles in Persistence. Rowlands et al. (1980, Cell 19:871) showed that all VSV proteins have altered peptide maps after 5 years of persistent infection, and the multiply mutated virus is so slow growing that it can now establish persistent infection without DI particle coinfection, although DI particles are quickly generated. Ahmed et al. (1980, J. Virol. 34:285 and 34:383) have shown genetic evidence for multiple mutations and the presence of extragenically suppressed $t s$ lesions resulting from reovirus persistence and in high passage stocks of wild-type virus. Henry et al. (1980, J. Gen. Virol. 47:343) have shown alterations in equine herpesvirus protein synthesis due to DI particles. Yogo et al. (1980, Virology 103:241) have shown the presence of free BK virus defective virus DNA in a hamster tumor induced by this human papovirus. Jones et al. (1980, Virology 103:158) have shown that the natural-killer (NK) cell response to cells persistently infected with VSV can be escaped by a number of different viral mutations. Horodyski and Holland (1980, J. Virol., in press) have found evidence for selection of standard virus mutants by DI particles during persistent VSV infection. Finally, Reid et al. (1980, Proc. Natl. Acad. Sci. USA, submitted for publication) showed that treatment of nude mice with anti-mouseinterferon antibody prevents rejection of persistently-infected tumor cells, and these rapidly form large tumors.

\section{ACKNOWLEDGMENTS}

We thank Deborah Spector, Jacques Perrault, and David Rowlands for helpful comments and careful reading of the manuscript. The research was supported by Grants USPHS AI15087 (IK) and A114627 (JH) and NSF PCM 77-19383 (IK). 


\section{REFERENCES}

Adachi, T., and Lazzarini, R. A., 1978, Elementary aspects of autointerference and the replication of defective interfering virus particles, Virology 87:152.

Adler, R., and Banerjee, A. K., 1976, Analysis of the RNA species isolated from defective particles of vesicular stomatitis virus, J. Gen. Virol. 33:51.

Ahmed, R., and Graham, A. F., 1977, Persistent infections in L cells with temperature sensitive mutants of reovirus, $J$. Virol. 23:250.

Baltimore, D., 1971, Expression of animal virus genomes, Bacteriol. Rev. 35:235.

Baltimore, D., Cole, C. N., Villa-Komaroff, L., and Spector, D., 1974, Poliovirus defective interfering particles, in: Mechanisms of Virus Disease: ICN-UCLA Symposia on Molecular and Cellular Biology, Vol. 1 (W. S. Robinson and C. F. Fox, eds), pp. 117-130, Academic Press, New York.

Bean, W. J., Jr., and Simpson, R. W., 1976, Transcriptase activity and genome composition of defective influenza virus, J. Virol. 18:365.

Bellett, A. J. D., and Cooper, P. D., 1959, Some properties of the transmissible interfering component of vesicular stomatitis virus preparations, J. Gen. Microbiol. 21:498.

Brown, F., Martin, S. J., Cartwright, B., and Crick, J., 1967, The ribonucleic acids of the infective and interfering components of vesicular stomatitis virus, J. Gen. Virol. 1:479.

Bruton, C. J., and Kennedy, S. I. T., 1976, Defective interfering particles of Semliki Forest virus: Structural differences between standard virus and defective interfering particles, J. Gen. Virol. 31:383.

Bruton, C. J., Porter, A., and Kennedy, S. I. T., 1976, Defective interfering particles of Semliki Forest virus: Intracellular events during interference, J. Gen. Virol. 31:397.

Chambers, V. C., 1957, The prolonged persistence of western equine encephalitis in cultures of strain L cells, Virology 3:62.

Choppin, P. W., 1969, Replication of influenza virus in a continuous cell line: High yield of infective virus from cells inoculated at high multiplicity, Virology 39:130.

Choppin, P. W., and Pons, M. W., 1970, The RNAs of infective and incomplete influenza virus grown in MDBK and HeLa cells, Virology 42:603.

Chow, J. M., Schnitzlein, W. M., and Reichmann, M. E., 1977, Expression of genetic information contained in the RNA of a defective interfering particle of vesicular stomatitis virus, Virology 77:579.

Clewley, J. P., Bishop, D. H. L., Kang, C. Y., Coffin, J., Schnitzlein, W. M., Reichmann, M. E., and Shope, R. E., 1977, Oligonucleotide fingerprints of RNA species obtained from rhabdoviruses belonging to the vesicular stomatitis virus subgroup, J. Virol. 23:152.

Cole, C. N., and Baltimore, D., 1973a, Defective interfering particles of poliovirus. 2. Nature of the defect, J. Mol. Biol. 76:325.

Cole, C. N., and Baltimore, D., 1973b, Defective interfering particles of poliovirus. 3. Interference and enrichment, J. Mol. Biol. 76:345.

Cole, C. N., and Baltimore, D., 1973c, Defective interfering particles of poliovirus. 4. Mechanisms of enrichment, J. Virol. 12:1414.

Cole, C. N., Smoler, D., Wimmer, E., and Baltimore, D., 1971, Defective interfering particles of poliovirus. 1. Isolation and physical properties, J. Virol. 7:478. 
Colonno, R. J., and Banerjee, A. K., 1976, A unique RNA species involved in initiation of vesicular stomatitis virus RNA transcription in vitro, Cell 8:197.

Colonno, R. J., and Banerjee, A. K., 1978, Complete nucleotide sequence of the leader RNA synthesized in vitro by vesicular stomatitis virus, Cell 15:93.

Colonno, R. J., Lazzarini, R. A., Keene, J. D., and Banerjee, A. K., 1977, In vitro synthesis of messenger RNA by a defective interfering particle of vesicular stomatitis virus, Proc. Natl. Acad. Sci. USA 74:1884.

Cooper, P. D., and Bellett, A. J. D., 1959, A transmissible interfering component of vesicular stomatitis virus preparations, J. Gen. Microbiol. 21:485.

Crick, J., and Brown, F., 1977, In vivo interference in vesicular stomatitis virus infection, Infect. Immun. 15:354.

Crick, J., Cartwright, B., and Brown, F., 1966, Interfering components of vesicular stomatitis virus, Nature (London) 211:1204.

Crowell, R. L., and Syverton, J. T., 1961, Poliovirus persistent infection in cell culture, J. Exp. Med. 113:419.

Davey, M. W., and Dalgarno, L., 1974, Semliki Forest virus replication in cultured Aedes albopictus cells: Studies on the establishment of persistence, J. Gen. Virol. 24:453.

Dimmock, N. J., and Kennedy, S. I. T., 1978, Protection of lethally infected mice with low doses of defective-interfering Semliki Forest virus, J. Gen. Virol. 39:231.

Doyle, M., and Holland, J. J., 1973, Prophylaxis and immunization in mice by use of virus-free defective $\mathrm{T}$ particles to protect against intracerebral infection by vesicular stomatitis virus, Proc. Natl. Acad. Sci. USA 70:2105.

Duesberg, P. H., 1968, The RNAs of influence virus, Proc. Natl. Acad. Sci. USA 59:930.

Eaton, B. T., 1975, Defective interfering particles of Semliki Forest virus do not interfere with viral RNA synthesis in Aedes albopictus cells, Virology 68:534.

Eaton, B. T., 1977, Evidence for the synthesis of defective interfering particles by Aedes albopictus cells persistently infected with Sindbis virus, Virology 77:843.

Faulkner, G., Dubois-Dalcq, M., Hoogke-Peters, E., McFarland, H. F., and Lazzarini, R. A., 1979, Defective interfering particles modulate VSV infection of dissociated neuron cultures, Cell 17:979.

Fernandes, M. V., Wiktor, T. J., and Koprowski, H., 1964, Endosymbiotic relationship between animal viruses and their host cells, J. Exp. Med. 120:1099.

Fields, B. N., 1972, Genetic manipulation of reovirus-A model for modification of disease? N. Engl. J. Med. 287:1026.

Graham, A. F., 1977, Possible role of defective virus in persistent infection, in: Microbiology 1977 (D. Schlessinger ed.). pp. 445-450, American Society for Microbiology, Washington, D.C.

Guild, G. M., and Stollar, V., 1975, Defective interfering particles of Sindbis virus. 3. Intracellular viral RNA species in chick embryo cell cultures, Virology 67:24.

Guild, G. M., and Stollar, V., 1977, Defective interfering particles of Sindbis virus. 5. Sequence relationships between $\mathrm{SV}_{\mathrm{STD}} 42 \mathrm{~S}$ RNA and intracellular defective viral RNAs, Virology 77:175.

Guild, G. M., Flores, L., and Stollar, V., 1977, Defective interfering particles of Sindbis virus. 4. Virion RNA species and molecular weight determination of defective double-stranded RNA, Virology 77:158. 
Hackett, A. J., 1964, A possible morphological basis for the autointerference phenomenon in vesicular stomatitis virus, Virology 24:51.

Hackett, A. J., Schaffer, F. L., and Madin, S. H., 1967, The separation of infectious and autointerfering particles in vesicular stomatitis virus preparations, Virology 31:114.

Hall, W. W., Martin, S. J., and Gould, E., 1974, Defective interfering particles produced during the replication of measles virus, Med. Microbiol. Immunol. 160: 155 .

Hall, W. W., Kiessling, W., and ter Meulen, V., 1978, Membrane proteins of subacute sclerosing panencephalitis and measles viruses, Nature (London) 272:460.

Hall, W. W., Lamb, R. A., and Choppin, P. W., 1979, Measles and subacute sclerosing panencephalitis virus proteins: Lack of antibodies to the $\mathrm{M}$ protein in patients with subacute sclerosing panencephalitis, Proc. Natl. Acad. Sci. USA 76:2047.

Henle, W., and Henle, G., 1943, Interference of inactive virus with the propagation of virus of influenza, Science 98:87.

Henry, B. E., Newcomb, W. W., and O'Callaghan, D. J., 1979, Biological and biochemical properties of defective interfering particles of equine herpesvirus type 1, Virology $92: 495$.

Hewlett, M. J., Petterson, R. F., and Baltimore, D., 1977, Circular forms of Uukuniemi virion RNA: An electron microscopic study, J. Virol. 21:1085.

Holland, J. J., and Doyle, M., 1973, Attempts to detect homologous autointerference in vivo with influenza virus and vesicular stomatitis virus, Infect. Immun. 7:526.

Holland, J. J., and Villarreal, L. P., 1974, Persistent noncytocidal vesicular stomatitis virus infections mediated by defective $\mathrm{T}$ particles that suppress virion transcriptase, Proc. Natl. Acad. Sci. USA 71:2956.

Holland, J. J., and Villarreal, L. P., 1975, Purification of defective interfering T particles of vesicular stomatitis and rabies viruses generated in vivo in brains of newborn mice, Virology 67:438.

Holland, J. J., Villarreal, L. P., and Breindl, M., 1976a, Factors involved in the generation and replication of Rhabdovirus defective T particles, J. Virol. 17:805.

Holland, J. J., Villarreal, L. P., Breindl, M., Semler, B. L., and Kohne, D., 1976b, Defective interfering virus particles attenuate virus lethality in vivo and in vitro, in: Animal Virology (D. Baltimore, A. S. Huang, and C. F. Cox, eds.), pp. 773-786, Academic Press, New York.

Holland, J. J., Villarreal, L. P., Welsh, R. M., Oldstone, M. B. A., Kohne, D., Lazzarini, R., and Scolnick, E., 1976c, Long-term persistent vesicular stomatitis virus and rabies virus infection of cells in vitro, J. Gen. Virol. 33:193.

Holland, J. J., Semler, B. L., Jones, C., Perrault, J., Reid, L., and Roux, L., 1978, Role of DI, virus mutation, and host response in persistent infections by envelope RNA viruses, in: Persistent Viruses (J. Stevens, G. Todaro, and C. F. Fox, eds.), pp. 57-73 Academic Press, New York.

Holland, J. J., Grabau, E., Jones, C. L., and Semler, B. L., 1979, Evolution of multiple genome mutations during long term persistent infection by vesicular stomatitis virus, Cell 16:495.

Huang, A. S., 1973, Defective interfering virus, Annu. Rev. Microbiol. 27:101.

Huang, A. S., 1977, Viral pathogenesis and molecular biology, Bacteriol. Rev. 41:811.

Huang, A. S., and Baltimore, D., 1970, Defective viral particles and viral disease processes, Nature (London) 226:325. 
Huang, A. S., and Baltimore, D., 1977, Defective interfering animal viruses, in: Comprehensive Virology, Vol. 10 (H. Fraenkel-Conrat and R. R. Wagner, eds.), pp. 73-116, Plenum Press, New York.

Huang, A. S., and Manders, E. K., 1972, Ribonucleic acid synthesis of vesicular stomatitis virus. 4 . Transcription by standard virus in the presence of defective intefering virus particles, J. Virol. 9:909.

Huang, A. S., and Wagner, R. R., 1966a, Defective T particles of vesicular stomatitis virus. 2. Biologic role in homologous interference, Virology 30:173.

Huang, A. S., and Wagner, R. R., 1966b, Comparative sedimentation coefficients of RNA extracted from plaque-forming and defective particles of vesicular stomatitis virus, J. Mol. Biol. 22:381.

Huang, A. S., Greenwalt, J. W., and Wagner, R. R., 1966, Defective T particles of vesicular stomatitis virus. 1. Preparation, morphology, and some biologic properties, Virology 30:161.

Huang, A. S. Little, S. P., Oldstone, M. B. A., and Rao, D., 1978, Defective interfering particles: Their effect on gene expression and replication of vesicular stomatitis virus, in: Persistent Viruses (J. Stevens, G. Todaro, and C. F. Fox, eds.), pp. 399-408, Academic Press, New York.

Igarashi, A., and Stollar, V., 1976, Failure of defective interfering particles of Sindbis virus produced in BHK or chicken cells to affect viral replication in Aedes albopictus cells, J. Virol. 19:398.

Igarashi, A., Koo, R., and Stollar, V., 1977, Evolution and properties of Aedes albopictus cell cultures persistently infected with Sindbis virus, Virology 82:69.

Inglot, A. D., and Chudzio, T., 1972, Incomplete Sindbis virus, in: Proceedings of the Second International Congress for Virology (J. L. Melnick, ed.), pp. 158-162, Karger, New York.

Inglot, A. D., Albin, M., and Chudzio, T., 1973, Persistent infection of mouse cells with Sindbis virus: Role of virulence of strains, auto-interfering particles and interferon, J. Gen. Virol. 20:105.

Ito, Y., Nishiyama, Y., Shimokata, K., Kimura, Y., Nagata, I., Shimizu, K., and Kunii, A., 1975, Interferon induction in mice by BHK cells persistently infected with HVJ, J. Gen. Virol. 27:93.

Janda, J. M., David, A. R., Nayak, D. P., and De, B. K., 1979, Diversity and generation of defective interfering influenza virus particles, Virology 95:48.

Johnson, L. D., and Lazzarini, R. A., 1977, Replication in viral RNA by a defective interfering vesicular stomatitis virus particle in the absence of helper virus, Proc. Natl. Acad. Sci. USA 74:4387.

Johnston, R. E., Jovell, D. R. Brown, D. T., and Falkner, P., 1975, Interfering passages of Sindbis virus: Concomitant appearance of interference, morphological variants and truncated viral RNA, J. Virol. 16:951.

Jones, C. L., and Holland, J. J., 1980, Requirements for DI particle prophylaxis against VSV infection in vivo, J. Gen. Virol. (in press).

Joseph, B. S., and Oldstone, M. B. A., 1975, Immunologic injury in measles infection. II. Suppression of immune injury through antigenic modulation, J. Expl. Med. 142:864.

Kang, C. Y., and Allen, R., 1978, Host function-dependent induction of defective interfering particles of vesicular stomatitis virus, J. Virol. 25:202.

Kang, C. Y., Glimp, T., Clewley, J. P., and Bishop, D. H. L., 1978, Studies on the 
generation of vesicular stomatitis virus (Indiana serotype) defective interfering particles, Virology 84:142.

Kawai, A., and Matsumoto, S., 1977, Interfering and noninterfering defective particles generated by a rabies small plaque variant virus, Virology 76:60.

Kawai, A., Matsumoto, S., and Tanabe, K., 1975, Characterization of rabies viruses recovered from persistently infected BHK cells, Virology 67:520.

Keene, J. D., Schubert, M., Lazzarini, R. A., and Rosenberg, M., 1978, Nucleotide sequence homology at the $3^{\prime}$ termini of RNA from vesicular stomatitis virus and its defective interfering particles, Proc. Natl. Acad. Sci. USA 75:3225.

Kennedy, S. I. T., 1976, Sequence relationships between the genome and the intracellular RNA species of standard and defective interfering Semliki Forest virus, J. Mol. Biol. 108:491.

Kennedy, S. I. T., Bruton, C. J., Weiss, B., and Schlesinger, S., 1976, Defective interfering passages of Sindbis virus: Nature of the defective virion RNA, J. Virol. 19:1034.

Khan, S. R., and Lazzarini, R. A., 1977, The relationship between autointerference and the replication of a defective interfering particle, Virology 77:189.

Kiley, M. P., Gray, R. H., and Payne, F. E., 1974, Replication of measles virus: Distinct species of short nucleocapsids in cytoplasmic extracts of infected cells, $J$. Virol 13:721.

Kimura, Y., Ito, Y., Shimokata, K., Nishiyama, Y., Nagata, I., and Kitoh, J., 1975, Temperature sensitive virus derived from BHK cells persistently infected with HVJ, J. Virol. 15:55.

Kingsbury, D. W., and Portner, A., 1970, On the genesis of incomplete Sendai virions, Virology 42:872.

Kingsbury, D. W., Portner, A., and Darlington, R. W., 1970, Properties of incomplete Sendai virions and subgenomic viral RNAs, Virology 42:857.

Kolakofsky, D., 1976, Isolation and characterization of Sendai virus DI RNAs, Cell 8:547.

Kolakofsky, D., 1979, Studies on the generation and amplification of Sendai virus DI genomes, Virology 93:589.

Kolakofsky, D., Leppert, M., and Kort, L., 1978, A genetic map of Sendai virus DI RNAs, in: Negative Strand Viruses and the Host Cell (B. W. J. Mahy and R. D. Barry, eds.), pp. 539-553, Academic Press, New York.

Lazzarini, R. A., Weber G. H., Johnson, L. D., and Stamminger, G. M., 1975, Covalently linked message and anti-message (genomic) RNA from a defective vesicular stomatitis virus particle, J. Mol. Biol. 97:289.

Leamnson, R. N., and Reichmann, M. E., 1974, The RNA of defective vesicular stomatitis virus in relation to viral cistrons, J. Mol. Biol. 85:551.

Lehmann-Grubbe, F., Slenzka, W., and Reef Tees, 1969, A persistent and inapparent infection of $\mathrm{L}$ cells with the virus of lymphocytic choriomeningitis, J. Gen.Virol. 5:63.

Leppert, M., Kort, L., and Kolakofsky, D., 1977, Further characterization of Sendai virus DI RNAs: A model for their generation, Cell 12:539.

Levin, J. G., Ramseur, J. M., and Grimley, P. M., 1973, Host effect on arbovirus replication: Appearance of defective interfering particles in murine cells, J. Virol. 12:1401. 
Lunquist, R. E., Sullivan, M., and Maizel, J. V., 1979, Characterization of a new isolate of poliovirus defective interfering particles, Cell 18:79.

Little, S. P., and Huang, A. S., 1977, Synthesis and distribution of VSV specific polypeptides in the absence of progeny production, Virology 81:37.

Logan, K. B., 1979, Generation of defective interfering particles of Semliki Forest virus in a clone of Aedes aldopictus (mosquito) cells, J. Virol. 30:38.

Marcus, P. I., and Sekellick, M. J., 1977, Defective interfering particles with covalently linked [ \pm ] RNA induce interferon, Nature (London) 266:815.

Marcus, P. I., Sekellick, M. J., Johnson, L. D., and Lazzarini, R. A., 1977, Cell killing by viruses. V. T ranscribing defective interfering particles of VSV function as cell killing particles, Virology 82:242.

McClure, M. A., Holland, J. J., and Perrault, J., 1980, Generation of defective interfering particles in picornaviruses, Virology 100:408.

McGeoch, D. J., and Dolan, A., 1979, Sequence of 200 nucleotides at the 3' terminus of the genome RNA of vesicular stomatitis virus, Cell 6:3199.

Meinkoth, J., and Kennedy, S. I. T., 1979, Semliki Forest virus persistence in mouse L929 cells, Virology 100:141.

Mims, C. A. C., 1956, Rift Valley fever in mice. 4. Incomplete virus: Its production and properties, Br.J. Exp. Pathol. 37:129.

Minato, N., Bloom, B. R., Jones, C., Holland, J. J., and Reid, L. M., 1979, Mechanism of rejection of virus persistently infected tumor cells by athymic nude mice, J. Exp. Med. 149:1117.

Mocarski, E. S., and Stinski, M. F., 1979, Persistence of the cytomegalovirus genome in human cells, J. Virol. 31:761.

Mudd, J. A., Leavitt, R. W., Kingsbury, D. T., and Holland, J. J., 1973, Natural selection of mutants of vesicular stomatitis virus by cultured cells of Drosophila melanogaster, J. Gen. Virol. 20:341.

Narayan, O., Griffin, D. E., Chase, J., 1977, Antigenic shift of Visna virus in persistently infected sheep, Science 197:376.

Nayak, D. P., Tobita, K., Janda, J. M., Davis, A. R., and De, B. K., 1978, Homologous interference mediated by defective interfering influence virus derived from a temperature-sensitive mutant of influenza virus, $J$. Virol 28:375.

Nicholson, B. L., and Dunn, J., 1972, Autointerference in the replication of the infectious pancreatic necrosis (IPN) virus of trout, Bacteriol. Proc. 72:196.

Nishiyama, Y., 1977, Studies of L cells persistently infected with VSV: Factors involved in the regulation of persistent infection, J. Gen. Virol. 35:265.

Nishiyama, Y., Ito, Y., Shimokata, K., Kimura, Y., and Nagata, J., 1976, Relationship between establishment of persistent infection of heamagglutinating virus of Japan and the properties of the virus, J. Gen. Virol. 32:73.

Nishiyama, Y., Ito, Y., and Shimokata, K., 1978, Properties of viruses selected during persistent infection of L cells with VSV, J. Gen. Virol. 40:481.

Nomoto, A., Jacobson, A., Lee, Y. F., Dunn, J., and Wimmer, E., 1978, Defective interfering particles of poliovirus: Mapping of the deletion and evidence that the deletion in the genome of DI (1), (2) and (3) is located in the same region. J. Mol. Biol. 128:179.

Nonoyama, M., and Graham, A. F., 1970, Appearance of defective virions in clones of reovirus, J. Virol. 6:693. 
Nonoyama, M., Watanabe, Y., and Graham, A. F., 1970, Defective virions of reovirus, J. Virol. 6:693.

Norkin, L. C., 1979, The emergence of simian virus 40 variants in a persistent infection of Rhesus monkey kidney cells, and their interaction with standard simian virus 40, Virology 95:598.

Obijeski, J. F., Bishop, D. H. L., Palmer, E. L., and Murphy, F. A., 1976, Segmented genome and nucleocapsid of La Crosse virus, J. Virol. 20:664.

Palma, E. L., and Huang, A. S., 1974, Cyclic production of vesicular stomatitis virus caused by defective interfering particles, J. Infect. Dis. 126:402.

Peleg, J., 1969, Inapparent persistent virus infection in continuously grown Aedes aegypti mosquito cells, J. Gen. Virol. 5:463.

Perrault, J., 1976, Cross-linked double-stranded RNA from a defective vesicular stomatitis virus particle, Virology 70:360.

Perrault, J., and Holland, J. J., 1972a, Variability of vesicular stomatitis virus autointerference with different host cells and virus serotypes, Virology 50:148.

Perrault, J., and Holland, J. J., 1972b, Absence of transcriptase activity or transcription-inhibiting activity in defective interfering particles of vesicular stomatitis virus, Virology 50:159.

Perrault, J., and Leavitt, R. W., 1977a, Characterization of snap-back RNAs in vesicular stomatitis defective interfering virus particles, J. Gen. Virol. 38:21.

Perrault, J., and Leavitt, R. W., 1977b, Inverted complementary terminal sequences in single-stranded RNAs and snap-back RNAs from vesicular stomatitis defective interfering particles, J. Gen. Virol. 38:35.

Perrault, J., and Semler, B. L., 1979, Internal genome deletions in two distinct classes of defective interfering particles of vesicular stomatitis virus, Proc. Natl. Acad. Sci. USA 76:6191.

Perrault, J., Semler, B. L., Leavitt, R. W., and Holland, J. J., 1978, Inverted complementary sequences in defective interfering particle RNAs of vesicular stomatitis virus and their possible role in autointerference, in: Negative Strand Viruses and the Host Cell (B. W. J. Mahy and R. D. Barry, eds.), pp. 527-538, Academic Press, New York.

Perrin, L., Tishon, A., and Oldstone, M. B. A., 1977, Immuniologic injury in measles virus infection. 3. Presence and characterization of human cytotoxic lymphocytes, J. Immunol. 118:282.

Petterson, R. F., and Hewlett, M. J., 1976, The structure of the RNA of Uukuniemi virus, a proposed Bunyavirus, in: Animal Virology (D. Baltimore, A. S. Huang, and C. F. Fox, eds.), pp. 515-527, Academic Press, New York.

Petterson, R. F., and Von Bonsdorff, C. H., 1975, Ribonucleoproteins of Uukuniemi virus are circular, J. Virol. 15:386.

Popescu, M., and Lehmann-Grube, F., 1977, Defective interfering particles in mice infected with lymphocytic choriomeningitis virus, Virology 77:78.

Preble, O. T., and Youngner, J. S., 1975, Temperature sensitive mutant viruses and the etiology of chronic and inapparent infections, J. Infect. Dis. 131:467.

Prevec, L., and Kang, C. Y., 1970, Homotypic and heterotypic interference by defective particles of vesicular stomatitis virus, Nature (London) 228:25.

Rabinowitz, S. G., Dal Canto, M. C., and Johnson, T. C., 1976, Comparison of central nervous system disease produced by wild type and temperature-sensitive mutants of vesicular stomatitis virus, Infect. Immun. 13:1242. 
Rahacek, J., 1968, Persistent infection of mosquito cells grown in vitro with Murray Valley encephalitis and Japanese encephalitis viruses, Acta Virol. 12:340.

Ramseur, J. M., and Friedman, R. M., 1977, Prolonged infection of interferon-treated cells by VSV: Possible role of temperature sensitive mutants and interferon, $J$. Gen. Virol. 37:523.

Reichmann, M. E., and Schnitzlein, W. M., 1978, Defective interfering particles of rhabdoviruses, Curr. Top. Microbiol. Immunol. 86:124.

Reichmann, M. E., Pringle, C. R., and Follett, E. A. C., 1971, Defective particles in BHK cells infected with temperature sensitive mutants of vesicular stomatitis virus, J. Virol. 8:154.

Reichmann, M. E., Villarreal, L. P., Kohne, D., Lesnaw, J., and Holland, J. J., 1974, RNA polymerase activity and poly(A) synthesizing activity in defective $\mathrm{T}$ particles of vesicular stomatitis virus, Virology 58:240.

Reid, L. M., Jones, C. L., and Holland, J., 1979, Virus carrier state suppresses tumorigenicity of tumor cells in athymic (nude) mice, J. Gen. Virol. 42:609:

Rima, B. K., and Martin, S. J., 1977, Persistent infection of tissue culture cells by RNA viruses, Med. Microbiol. Immunol. 162:89.

Rima, B. K., and Martin, S. J., 1979, Effect of undiluted passage on the polypeptides of measles virus, J. Gen. Virol. 44:135.

Rima, B. K., Davidson, W. B., and Martin, S. J., 1977, The role of defective interfering particles in persistent infection of vero cells by measles, J. Gen. Virol. 35:89.

Roux, L., and Holland, J. J., 1979, Role of defective interfering particles of Sendai virus in persistent infections, Virology 93:91.

Roux, L., and Holland, J. J., 1980, Viral genome synthesis in BHK21 cells persistently infected with Sendai virus, Virology 100:53.

Rowlands, D. J., 1979, Sequences of VSV RNA in the region coding for leader RNA, N m RNA and their function, Proc. Natl. Acad. Sci. USA 76:4793.

Roy, P., and Bishop, D. H. L., 1972, Genome homology of vesicular stomatitis virus and defective $\mathrm{T}$ particles and evidence for the sequential transcription of the virion ribonucleic acid, J. Virol. 9:946.

Roy, P., Repik, P., Hefti, E., and Bishop, D. H. L., 1973, Complementary RNA species isolated from vesicular stomatitis (HR) strain defective virions, J. Virol. 11:915.

Samso, A., Bouloy, M., and Hannoun, C., 1975, Présence de ribonucléoproteines circulaires dans le virus Lumbo (Bunyavirus), C. R. Acad. Sci. Ser. D 280:213.

Schaffer, F. L., Hackett, A. J., and Soergel, M. E., 1968, Vesicular stomatitis virus RNA: Complementarity between infected cell RNA and RNAs from infectious and autointerfering viral fractions, Biochem. Biophys. Res. Commun. 31:685.

Schincariol, A. L., and Howatson, A. F., 1972, Replication of vesicular stomatitis virus. 2. Separation and characterization of virus-specific RNA species, Virology 49:766.

Schlesinger, S., Schlesinger, M., and Burge, B. W., 1972, Defective virus particles from Sindbis virus, Virology 48:615.

Schmaljohn, C., and Blair, C. D., 1977, Persistent infection of cultured mammalian cells by Japanese encephalitis virus, $J$. Virol. 24:580.

Schnitzlein, W. M., and Reichmann, M. E., 1976, the size and cistronic origin of defective vesicular stomatitis virus particle RNAs in relation to homotypic and heterotypic interference, J. Mol. Biol. 101:307. 
Schnitzlein, W. M., and Reichmann, M. E., 1977, A possible effect of viral proteins on the specificity of interference by defective vesicular stomatitis virus particles, Virology 80:275.

Schubert, M., Keene, J. D., Lazzarini, R. A., and Emerson, S. U., 1978, The complete sequence of a unique RNA species synthesized by a DI particle of VSV, Cell 15:103.

Schubert, M., Keene, J. D., and Lazzarini, R. A., 1979, A specific internal RNA polymerase recognition site of VSV RNA is involved in the generation of DI particles, Cell 18:749.

Schuerch, A. R., Matsuhisa, T., and Joklik, W. K., 1974, Temperature-sensitive mutants of reovirus. 6. Mutant ts 447 and ts556 particles that lack either one or two genome segments, Intervirology 3:36.

Semler, B. L., Perrault, J., Abelson, J., and Holland, J. J., 1978, Sequence of a RNA templated by the 3 '-OH RNA terminus of defective interfering particles of vesicular stomatitis virus, Proc. Natl. Acad. Sci. USA 75:4704.

Semler, B. L., Perrault, J., and Holland, J. J., 1979, The nucleotide sequence of the 5' terminus of vesicular stomatitis virus RNA, Nucl. Acids Res. 6:3923.

Shenk, T. E., and Stollar, V., 1973, Defective interfering particles of Sindbis virus. 1. Isolation and some chemical and biological properties, Virology 53:162.

Simpson, R. W., and Iinuma, M., 1975, Recovery of infectious proviral DNA from mammalian cells infected with respiratory syncitial virus, Proc. Natl. Acad. Sci. USA 72:3230.

Singh, K. R. P., 1967, Cell cultures derived from larvae of Aedes albopictus (SRuse) and Aedes aegypti (L), Curr. Sci. 36:506.

Spandidos, D. A., and Graham, A. F., 1976, Generation of defective virus after infection of newborn rats with reovirus, J. Virol. 20:234.

Spandidos, D. A., Krystal, G., and Graham, A. F., 1976, Regulated transcription of the genomes of defective virions and temperature-sensitive mutants of reovirus, $J$. Virol. 18:7.

Stamminger, G., and Lazzarini, R. A., 1974, Analysis of the RNA of defective VSV particles, Cell 3:85.

Stamminger, G. M., and Lazzarini, R. A., 1977, RNA synthesis in standard and autointerfered vesicular stomatitis infections, Virology 77:202.

Stampfer, M., Baltimore, D., and Huang, A. S., 1971, Absence of interference during high multiplicity infection by clonally purified vesicular stomatitis virus, J. Virol. 7:409.

Staneck, L. D., and Pfau, C. J., 1974, Interfering particles from a culture persistently infected with parana virus, J. Gen. Virol. 22:437.

Staneck, L. D., Trowbridge, R. S., Welsh, R. M., Wright, E. A., and Pfau, C. J., 1972, Arenaviruses: Cellular response to long-term in vitro infection with parana and lymphocytic choriomeningitis viruses, Infect. Immun. 6:444.

Stanners, C. P., and Goldberg, V. J., 1975, On the mechanism of neurotropism of VSV in newborn hamsters. Studies with temperature-sensitive mutants, J. Gen. Virol. 29:281.

Stanners, C. P., Francoeur, A. M., and Larn, T., 1977, Analysis of VSV mutant with attenuated cytopathogenicity: Mutation in viral function $\mathbf{P}$ for inhibition of protein synthesis, Cell 11:273.

Stanwick, T. L., and Kirk, B. F., 1976, Analysis of baby hamster kidney cells 
persistently infected with lymphocytic choriomeningitis virus, J. Gen. Virol. 32:361.

Stark, C., and Kennedy, S. I. T., 1978, The generation and propagation of defective interfering particles of Semliki Forest virus in different cell types, Virology 89:285.

Stevens, J., 1978, Latent herpetic infections in the central nervous system of experimental animals, in: Persistent Viruses (J. Stevens, G. J. Todaro, and C. F. Fox, eds.), p. 701, Academic Press, New York.

Stevens, T. M., 1970, Arbovirus replication in mosquito cell lines (Singh) grown in monolayer or suspension culture, Proc. Soc. Exp. Biol. Med. 134:356.

Stinski, M. F., Mocarski, E. S., and Thomsen, D. R., 1979, DNA of human cytomegalovirus: Size heterogeneity and defectiveness resulting from serial undiluted passages, $J$. Virol. 31.231.

Stollar, V., and Shenk, T. E., 1973, Homologous viral interference in Aedes albopictus cultures chronically infected with Sindbis virus, J. Virol. 11:592.

Taber, R., Alexander, V., and Whitford, W., 1976, Persistent reovirus infection of CHO cells resulting in virus resistance, $J$. Virol. 17:513.

Thorne, H. V., and Dermott, E., 1976, Circular and elongated forms of measles virus nucleocapsid, Nature (London) 264:473.

Trowbridge, R. S., and Pfau, C. J., 1970, Persistent infection of cultured BHK $\mathrm{K}_{21} / 13 \mathrm{C}$ cells by lymphocytic choriomeningitis virus, Bacteriol. Proc., p. 199.

Villarreal, L. P., and Holland, J. J., 1976, RNA synthesis in $\mathrm{BHK}_{21}$ cells persistently infected with vesicular stomatitis virus and rabies virus, J. Gen. Virol. 33:213.

Von Magnus, P., 1951, Propagation of the PR 8 strain of influenza virus in chick embryos. 3. Properties of the incomplete virus produced in serial passages of undiluted virus, Acta Pathol. Microbiol. Scand. 29:156.

von Magnus, P., 1954, Incomplete forms of influenza virus, Adv. Virus Res. 2:59.

Wagner, R. R., 1974, Pathogenicity and immunogenicity for mice of temperature sensitive mutants of vesicular stomatitis virus, Infect. Immun. 10:309.

Wagner, R. R., 1975, Reproduction of rhabdoviruses, in: Comprehensive Virology, Vol. 4 (H. Fraenkel-Conrat and R. R. Wagner, eds.), pp. 1-93, Plenum Press, New York.

Wagner, R. R., Levy, A., Snyder, R., Ratcliff, G., and Hyatt, D., 1963, Biologic properties of two plaque variants of vesicular stomatitis virus (Indiana serotype), $J$. Immunol. 91:112.

Walker, D. L., 1964, The viral carrier state in animal cultures, Progr. Med. Virol. 6:111.

Wechsler, S. L., and Fields, B. N., 1978, Differences between the intracellular polypeptides of measles and subacute sclerosing panencephalitis virus, Nature (London) 272:458.

Weiss, B., and Schlesinger, S., 1973, Defective interfering passages of Sindbis virus: Chemical composition, biological activity and mode of interference, J. Virol. 12:862.

Weiss, B., Goran, D., Cancedda, R., and Schlesinger, S., 1974, Defective interfering passages of Sindbis virus: Nature of the intracellular defective viral RNA, J. Virol. 14:1189.

Weiss, B., Rosenthal, R., and Schlesinger, S., 1980, Establishment and maintenance of persistent infection by Sindbis virus in BHK cells, J. Virol. 33:463.

Welsh, R. M., and Oldstone, M. B. A., 1977, Inhibition of immunologic injury of cul- 
tured cells infected with lymphocytic choriomeningitis virus: Role of defective interfering virus in regulating viral antigenic expression, J. Exp. Med. 145:1449.

Welsh, R. M., and Pfau, C. J., 1972, Determinants of lymphocytic choriomeningitis interference, J. Gen. Virol. 14:177.

Welsh, R. M., O'Connell, C. M., and Pfau, C. J., 1972, Properties of defective lymphocytic choriomeningitis virus, J. Gen. Virol. 17:355.

Welsh, R. M., Lampert, P. W., and Oldstone, M. B. A., 1977, Prevention of virusinduced cerebral disease by defective interfering lymphocytic choriomeningitis virus, J. Infect. Dis. 136:391.

Wiktor, T. J., and Clark, H. F., 1972, Chronic rabies virus infection of cell cultures, Infect. Immun. 6:988.

Wiktor, T. J., Dietyzsehold, B., Leamnson, R. N., and Koprowski, H., 1977, Induction and biological properties of defective interfering particles of rabies virus, J. Virol. 21:626.

Wild, T. F., and Dugre, R., 1978, Establishment and characterization of a subacute sclerosing panencephalitis (measles) virus persistent infection in BGM cells, $J$. Gen. Virol 39:113.

Wilfert, C. M., Buckley, R., Rosen, F. S., Whismant, J., Oxman, M. N., Griffith, J. F., Katz, S. L., and Moure, M., 1977, Persistent enterovirus infections in agammaglobulinemia, in: Microbiology 1977 (D. Schlesinger, ed.), pp. 488-493, American Society for Microbiology, Washington, D.C.

Wunner, W. H., and Clark, H. F., 1978, Study of virulent and avirulent rabies viruses and their defective RNA-containing particles, in: Negative Strand Viruses and the Host Cell (B. Mahy and R. Barry, eds.), pp. 599-606, Academic Press, London.

Yamada, T., and Hatano, M., 1972, Lowered transplantability of cultured tumor cells by persistent infection with paramyxovirus (HVJ), Gann 63:647.

Youngner, J. S., and Quagliana, D. O., 1975, Temperature-sensitive mutants isolated from hamster and canine cell lines persistently infected with Newcastle disease virus, J. Virol. 16:1332.

Youngner, J., Dubovi, E. J., Quagliana, D. O., Kelly, M., and Preble, O. T., 1976, Role of temperature sensitive mutants in persistent infections initiated with vesicular stomatitis virus, $J$. Virol. 19:90.

Zhdanov, V. M., 1975, Integration of viral genomes, Nature (London) 256:471. 